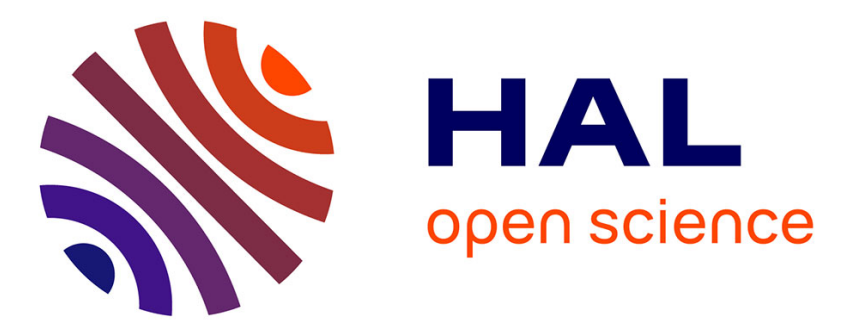

\title{
Experimental and numerical characterization of an impure phase change material using a thermal lattice Boltzmann method
}

\author{
Alissar Yehya, Hassane Naji, Laurent Zalewski
}

\section{To cite this version:}

Alissar Yehya, Hassane Naji, Laurent Zalewski. Experimental and numerical characterization of an impure phase change material using a thermal lattice Boltzmann method. Applied Thermal Engineering, 2019, 10.1016/j.applthermaleng.2019.03.026 . hal-03246384

\author{
HAL Id: hal-03246384 \\ https://hal.science/hal-03246384
}

Submitted on 22 Oct 2021

HAL is a multi-disciplinary open access archive for the deposit and dissemination of scientific research documents, whether they are published or not. The documents may come from teaching and research institutions in France or abroad, or from public or private research centers.
L'archive ouverte pluridisciplinaire HAL, est destinée au dépôt et à la diffusion de documents scientifiques de niveau recherche, publiés ou non, émanant des établissements d'enseignement et de recherche français ou étrangers, des laboratoires publics ou privés.

\section{(ㄷ)(1) $\$$}

Distributed under a Creative Commons Attribution - NonCommerciall 4.0 International 


\section{Experimental and numerical characterization of an impure phase change material using a thermal lattice Boltzmann method}

Alissar Yehya $^{\text {a, b }}$, Hassane Naji ${ }^{\mathbf{c}, \mathbf{d}, \mathbf{1}}$, Laurent Zalewski ${ }^{\mathbf{c}, \mathbf{d}}$

a Harvard John A. Paulson School of Engineering and Applied Sciences, MA 02138, Cambridge, USA

b American University of Beirut (AUB), Department of Chemical and Petroleum Engineering, MSFEA, Lebanon

c Univ. Artois, Civil Engineering \& Geo-Environment Laboratory (LGCgE- EA 4515), Technoparc Futura, F-62400 Béthune, France

d Northern Lille University France, LGCgE- EA 4515, FR-59000 Lille, France

\section{$12 \quad$ Email addresses:}

13 alissar_yehya@seas.harvard.edu; ay36@aub.edu.lb

14 hassane.naji@univ-artois.fr

15 laurent.zalewski@univ-artois.fr

\section{ORCIDs iD:}

17 Alissar Yehya https://orcid.org/0000-0001-9956-3636

18 Hassane Naji http://orcid.org/0000-0002-5994-7958

19 Laurent Zalewski https://orcid.org/0000-0002-7298-3224

\footnotetext{
${ }^{1}$ Corresponding author at Univ. Artois, Laboratoire Génie Civil \& géo-Environnement (LGCgE - EA 4515) Technoparc Futura, F-62400 Béthune, France.

E-mail address: hassane.naji@univ-artois.fr (H. Naji).

Tel.: + 33611267983
} 
21 Towards experimental and numerical characterization of an impure phase change material using a thermal lattice Boltzmann method Abstract

23 Of the phase change materials (PCMs) that regulate ambient temperature while reducing energy

24 consumption, Octadecane is a good candidate because of its transparency properties and its

25 adequate melting temperature. This study aims to characterize, through an approach combining

26 numerical simulation and experiment, the behavior and thermo-physical properties of $\mathrm{n}$ -

27 Octadecane. The approach takes into consideration the natural convection and the use of PCM's

28 experimentally-obtained enthalpy-temperature curve that includes the supercooling and soluble

29 impurities effects. The model uses the thermal lattice Boltzmann method based both on a partial

30 bounce-back and an enthalpy formulation while including the experimental relationships. The

31 numerical and experimental results exhibit good agreement. The approach adopted allows to

32 highlight the behavior of the PCM to better characterize its thermo-physical properties.

33 Keywords: Phase change materials (PCMs), Lattice Boltzmann method (LBM), Convection, 34 Supercooling, Impurities. 


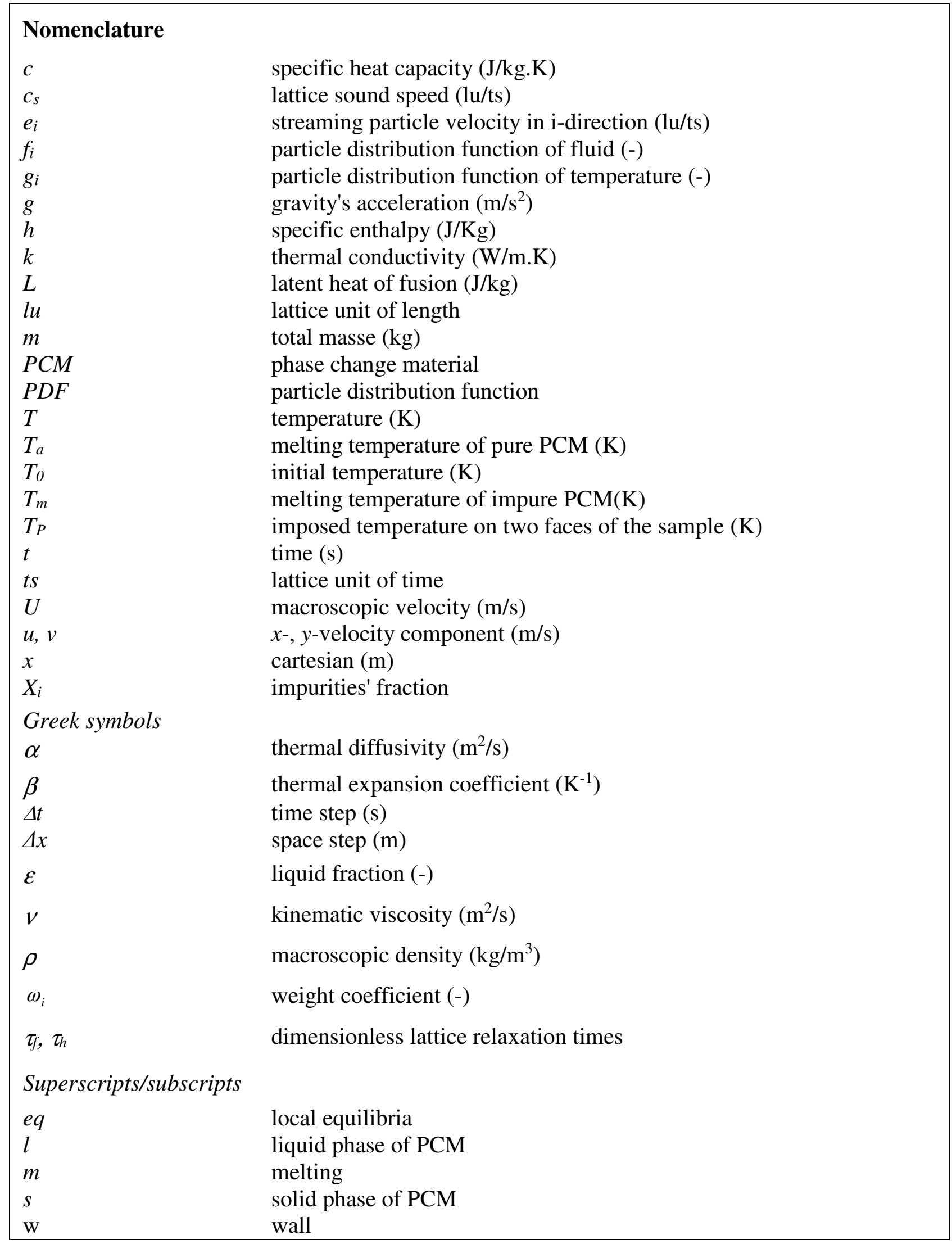




\section{Introduction}

The global population growth has led to a high energy demand and increased $\mathrm{CO}_{2}$ emissions triggering a major environmental crisis. The energy use in buildings accounts for a large share of

40 the total end use of energy, with an average consumption of about $50 \%$ of all raw materials owned

41 in the world [1]. This percentage would differ depending on the region, and is equal to $40 \%$ in

42 Europe, $30 \%$ in USA, and reaches $70 \%$ in undeveloped countries [2]. Energy consumption for 43 thermal comfort in buildings rises with increasing in user demand for comfort conditions. This rise

44 in, both, energy consumption and $\mathrm{CO}_{2}$ emissions thus promoted a new policy aimed at creating 45 more sustainable buildings [3]. Scientists all over the world are in search of new and renewable energy sources. One of the options is to develop energy storage devices, which are as important as

47 developing new sources of energy. Thermal energy storage does not only reduce the temporal gap 48 between supply and demand, but it also improves the performance of energy systems and plays a 49 significant role in conserving energy [4]. Such storage can be achieved either by using sensible 50 heat or thermo-chemical heat or latent heat. Among these different methods, the latent thermal 51 energy storage (LTES) method, using phase change materials (PCMs), is the most preferred and 52 the most widely used at present [5, 6] mainly for their application for heating and cooling of 53 buildings [4, 7-11]. PCMs can be used for temperature regulation and their high storage capacity 54 can reduce energy consumption in buildings, and thereby contribute to the reduction of $\mathrm{CO}_{2}$ 55 emissions.

56 Recently, interest in the use of Octadecane in latent heat systems and building materials has

57 increased. Its choice is mainly due to its transparency properties and its melting temperature, which

58 lies within the thermal comfort of human beings. The original idea is to fill Plexiglas enclosures 59 with PCM having transparency properties, and thereby create a wall of a building façade or 60 windows that benefits from solar gains. For PCMs in windows, paraffin-based organic materials 61 are the most interesting since they are transparent in the liquid state and translucent in the solid 62 state. For that, it is interesting to investigate more on Octadecane as a PCM. The main task 
throughout this research is to develop a numerical model that matches the experimental results and

64 helps infer some thermo-physical properties that are difficult to predict via single experiments,

65 example: the thermal contact resistance, conductivity in liquid phase, the degree of supercooling,

66 heat transfer coefficient, etc. Following this, the model can be also used to enhance and optimize

67 PCM performance in practical applications. Note that, at this stage, the heat transfer by radiation

68 is not considered since our experimental apparatus induces heat through attached plates controlled

69 by thermo-regulated baths (see Section 4). Actually, the study of such materials will involve the

70 characterization part, as our present study, and an application part where the experimental setup

71 will be different and will follow appropriate climatic and external conditions and adequate

72 geometric scales. Both tests and studies are required for this material to reach a mature state for

73 practical applications.

74 Thus, prior to the large-scale practical application of this technology, it is crucial to consider

75 certain issues in the stage of research and development [4]. The experimental investigation of some

76 PCMs showed the presence of some phenomena that could affect the performance if not considered

77 in the design, namely supercooling, convection and impurities. When supercooling occurs, the start

78 of solidification is delayed, and the liquid solidifies at a temperature below its freezing temperature.

79 This can lead to a mismatch between the design and the real behavior of the PCM [12]. Most of the

80 theoretical heat transfer modeling of PCM energy storage systems is based on the conjecture that

81 the supercooling degree is negligible or even completely absent. However, recently published

82 researches [12-14] indicate that even a relatively small degree of supercooling might result in a

83 significant undesirable effect on the heat release rate as a function of time, reducing the thermal

84 efficiency of the system. Therefore, it is important to provide reliable theoretical modeling of

85 supercooling in PCM for a more adequate design.

86 Another important phenomenon, ignored in some numerical models, is the natural convection

87 in the liquid phase. If PCMs with high Prandtl number are used, e.g. Octadecane, it is very likely

88 to have convection even in small samples. This is because the relative thickness of the momentum 
boundary layer is much more than the thermal one. Hence, convection will be dominant with momentum diffusing more quickly compared to heat. In addition, soluble impurities, if they exist,

91 may lead to depression in melting point thus altering the temperature-enthalpy curve, so that the

92 traditional piecewise function can no longer be used. Also, the thermal contact between different

93 materials in the system can have similar effects on the enthalpy curve. Therefore, using a simplified

94 model may fail to successfully predict the phase change process, if the aforementioned phenomena

95 are present. Thereby, the main aim targeted here is to provide an improved model that accounts for 96 supercooling, convection and the modified enthalpy-temperature curve. To carry out this work, we 97 consider the thermal lattice Boltzmann method (TLBM) [15-20] based on a partial bounce-back 98 (PBB) approach [21-23] supplemented with an enthalpy-based model. This enhanced model 99 provides a more accurate simulation of phase-change materials, can better predict the solidification 100 and melting processes, and thus match the experimental results.

101 The paper is organized as follows: Section 2 provides a literature review on challenges in 102 modeling phase-change materials. Section 3 is devoted to the lattice Boltzmann method adopted 103 herein to achieve the numerical solution while supplementing the appropriate enhancements. The 104 experimental setup with equipment and the measurement method is outlined in Section 4. Section 1055 presents the experimental determination of the thermo-physical properties of Octadecane: 106 conductivities, specific capacities, latent heat of fusion, and the analysis of the heat flux curves. 107 Thorough discussions of the confrontation between numerical and experimental results are 108 presented in Section 6. Finally, Section 7 concludes the paper by providing key findings based on 109 the dual experimental and numerical approach.

\section{2. Challenges of modeling of phase-change materials}

111 PCMs have various possible applications ranging from temperature stabilization to energy 112 storage. Though many pure chemical elements can be used as PCMs, the majority often consists of 113 a mixture, or contains at least soluble impurities. The main reason for creating a PCM as a mixture 114 of various substances is to achieve a desirable melting temperature for a particular application. 
115 However, these mixed or impure PCMs require accurate and reliable methods for determining their

116 thermo-physical properties, which represents a significant issue that considerably affects the

117 accuracy and credibility of the corresponding studies. Numerical modeling can help in determining

118 some of these properties. However, other serious complexities interfere in the modeling of phase 119 change materials, which makes it a real challenge.

120 Many macroscopic mathematical modeling schemes for solidification/melting problems can be

121 found in the literature [23-25]. Early efforts initiated with the moving/deforming grid approach [24,

122 25] in which independent conservation equations for each phase are initially formulated and are

123 subsequently coupled with appropriate boundary conditions at the interfaces. However, such

124 multiple region solutions require the existence of discrete interfaces between the respective phases.

125 In fact, a major difficulty in their implementation [26] is associated with tracking the phase 126 interfaces (which are generally unknown functions of space and time). Additionally, a serious

127 limitation exists for modeling phase change behavior of multi-component systems, since they do 128 not exhibit a sharp interface between solid and liquid phases. Moreover, solidification occurs over 129 extended temperature ranges and solid formation often occurs as a permeable crystalline-like 130 matrix, which coexists with the liquid phase. Otherwise, there are the fixed-grid models, using 131 finite element (FE) or finite volume (FV) methods [24, 27]. A separate equation for the liquid 132 fraction evolution is solved, which implicitly specifies and updates the interfacial locations with 133 respect to space and time. The fixed grid method is relatively simple, versatile, practical, adaptable 134 and easily programmable [11]. It can easily handle melting or solidifying materials over a range of 135 temperatures. The latent heat evolution is accounted for in the governing equation by using, either 136 enthalpy method [12, 23], heat capacity method [13, 28], temperature transforming model [14], 137 heat source method [24, 25], or other methods.

138 On the other hand, the multi-scale mesoscopic lattice Boltzmann method (LBM) has emerged 139 to offer huge potential for solving complex thermo-fluidic problems involving morphological 
140 development of complicated phase boundaries [21-23, 29-33] and recovers the Navier-Stokes and

141 energy equations. In addition, it has been witnessed that the LBM stands out in major fields of

142 classical fluid dynamics: multiple-scale flows and heat transfers with or without phase change

143 process. Its advantage, compared to a classical based-continuum formulation, is that it operates at

144 a mesoscopic level, which incorporates micro and meso-scale physics of phase transitions, and

145 bypasses the explicit calculation of the pressure equation, leading to time-efficient computational

146 simulations. Further, LBMs are inherently transient and parallelizable, which renders their

147 suitability to address phase change processes over large-scale computational domains [34].

148 Moreover, by adopting partial bounce-back approach with enthalpy formulation [15], LBM treats

149 phase-change as flow in porous medium. Extensive work has been done to simulate fluid and heat

150 flow in porous media using LBM $[35,36]$. The liquid fraction calculated through an enthalpy

151 formulation designates the porosity in the mushy zone and helps tracking fusion front and

152 simulating convection. The local nature of the method allows adding local complexities where

153 necessary.

\section{3. Numerical Model}

\section{3.1. Enthalpy-temperature relationship}

156 The most common enthalpy/temperature relationship is often translated as a piecewise function

157 in the case of pure materials. However, even a small amount of impurities can lead to a significant 158 change in the enthalpy curve shape, with a depression of the melting temperature followed up by a 159 melting range. Hence, melting point analysis can provide information on the sample purity [37]. In 160 other words, a substance including soluble impurities will be prone to "melting point depression".

161 This is related to the intermolecular forces within the material. As the solid impurity increases, its 162 structure will be more disrupted, and hence will result in a greater variation in intermolecular forces 163 throughout different areas of the solid. The effect will be that the melting temperature is lower than 
that of a pure material, and the solid melts over a wider range of temperatures. Note that this is not the case for insoluble impurities. The latter will have no effect on the compound's melting point.

When soluble impurities exist, the model can be dealt as a binary mixture, with one component

167 having very small portion compared to the other. Thereby, we can calculate the depression in the 168 melting temperature $\left(\Delta T_{a m}\right)$ as follows [37]:

$$
\Delta T_{a m}=T_{a}-T_{m}=R T_{a}^{e} X_{i} / L_{f}
$$

170 where $T_{a}$ is the melting point of a $100 \%$ pure material, $T_{m}$ is the lowered melting point of the impure

171 material, $L_{f}(\mathrm{~J} / \mathrm{mol})$ is the molar heat of fusion, $R(=8.314 \mathrm{~J} / \mathrm{mol} / \mathrm{K})$ is the ideal gases universal 172 constant, and $X_{i}$ is impurities' fraction in the considered material. In this work, this can be used as

173 a pre-estimate of the real melting temperature of the studied sample with respect to the expected 174 melting temperature in literature.

175 It seems obvious that impurities' percentage in a material alters the enthalpy curve of a substance 176 and consequently affects the resulting heat flux. The peak of the heat flux curves becomes wider 177 and shorter as the impurity increases while maintaining the same underlying area (under it), which 178 is related to the melting enthalpy.

\section{Enthalpy-temperature relationship for pure PCMs}

180 The variation of enthalpy vs. temperature of a pure material is:

$$
\frac{d h_{p c m}}{d T}=\left\{\begin{array}{lll}
c_{s, p c m} & \text { for } & T<T_{a} \\
c_{l, p c m} & \text { for } & T>T_{a}
\end{array}\right.
$$

182 It should be noted that $d h_{p o m} / d T$ tends to infinity when $\mathrm{T}$ approaches $\mathrm{T}_{\mathrm{a}}$.

\section{- Enthalpy-temperature relationship for non-pure PCMs, i.e. with soluble impurities}

184 For an impure material, the variation of the enthalpy vs. temperature can be written as [38-40]:

$$
\frac{d h_{p c m}}{d T}=\left\{\begin{array}{rrr}
c_{s, p c m}-\left(c_{s, p c m}-c_{l, p c m}\right) \frac{T_{m}-T_{a}}{T-T_{a}}-L_{f} \frac{T_{m}-T_{a}}{\left(T-T_{a}\right)^{2}} & \text { for } & T \leq T_{m} \\
c_{l, p c m} & \text { for } & T>T_{m}
\end{array}\right.
$$


The resulting expression of the enthalpy becomes:

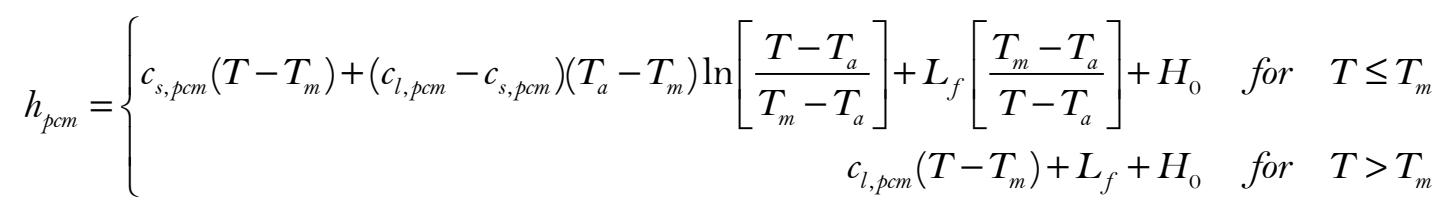

where $T_{a}$ and $T_{m}$ are the melting temperatures of pure and impure PCMs, respectively. However, $L_{f}$ is the latent heat of fusion, $H_{0}$ is the enthalpy at $T_{E}$, which denotes the onset of melting.

\subsection{Thermal lattice Boltzmann model (TLBM)}

The Lattice Boltzmann method (LBM) is a mesoscale discrete model that has become an increasingly popular tool for simulating fluid flows with and without heat transfers [15-20]. It consists of simulating the statistical behavior of a set of particles on a lattice with finite velocities. This evolution is carried out in a cycle of "streaming" (advection) and "collision" steps. The essential interpretation of such an approach is that it is a special finite difference form of the continuous Boltzmann equation. Furthermore, it allows providing macroscopic fluid properties, such as density, velocity, pressure, etc., through weighted averages, or moments, of the particle distribution for all discrete lattice velocities. The single relaxation time (SRT) lattice Boltzmann model (also called the lattice Bhatnagar-Gross-Krook (LBGK) model) [41, 42] for incompressible thermal flows leans on two distribution functions (DFs) with their corresponding evolution equations to solve the evolution of the two mesoscopic particle distribution functions, $f_{i}$ and $g_{i}$, via the discretized lattice Boltzmann equation as following:

$$
\begin{aligned}
& f_{i}\left(x+e_{i}, t+1\right)=f_{i}(x, t)-\tau_{f}^{-l}\left(f_{i}(x, t)-f_{i}^{e q}(x, t)\right)-\tau_{f} \beta g\left(T-T_{0}\right) / \rho \Delta T \\
& g_{i}\left(x+e_{i}, t+l\right)=g_{i}(x, t)-\tau_{h}^{-l}\left(g_{i}(x, t)-g_{i}^{e q}(x, t)\right)+S_{h}^{g}
\end{aligned}
$$

where $e_{i}$ is the microscopic particle velocity in the $i$-direction, $\tau_{f}$ and $\tau_{h}$ are the dimensionless relaxation times, and $f_{i}^{e q}$ and $g_{i}^{e q}$ are local equilibrium distributions functions that can be computed from: 


$$
f_{i}^{e q}=\rho \omega_{i}\left[1+\frac{3\left(\vec{e}_{i} \cdot \vec{U}\right)}{c_{s}^{2}}+\frac{9\left(\vec{e}_{i} \cdot \vec{U}\right)^{2}}{2 c_{s}^{4}}-\frac{3(\vec{U} \cdot \vec{U})}{2 c_{s}^{2}}\right]
$$

$209 \quad$ and $g_{i}^{e q}=T \omega_{i}\left[1+\frac{\vec{e}_{i} \cdot \vec{U}}{c_{s}^{2}}\right]$

210 where $\omega_{i}=\left\{\begin{array}{lll}4 / 9 & \text { for } & i=0 \\ 1 / 9 & \text { for } & i=2,4,6,8 \\ 1 / 36 & \text { for } & i=1,3,5,9\end{array} \quad\right.$ and $\quad e_{i}=\left\{\begin{array}{lll}(0,0) & \text { for } & i=0 \\ (0, \pm 1) & \text { for } & i=2,4 \\ ( \pm 1,0) & \text { for } & i=1,3 \\ ( \pm 1, \pm 1) & \text { for } & i=5,6,7,8\end{array}\right.$

211 are, respectively, the weight coefficient and the velocity vector of the $D_{2} Q_{9}$ model; $\vec{U}(u, v)$ is the 212 macroscopic velocity, with, $u$ and $v$ representing velocities in the $x_{-}$and $y$-directions, 213 respectively. Note that the relaxation times $\tau_{f}$ and $\tau_{h}$ can be determined via $v_{\text {latice }}=c_{s}^{2} \Delta t\left(\tau_{f}-0.5\right)$

214 and $\alpha_{\text {lattice }}=c_{s}^{2} \Delta t\left(\tau_{h}-0.5\right), c_{s}$ being the lattice sound speed. It should be noted that, the lattice

215 viscosity and thermal diffusivity are selected so as to conform to the intended Prandtl number $\operatorname{Pr}$

$216\left(=v_{\text {lattice }} / \alpha_{\text {latice }}\right)$. Likewise, the additional force term related to Boussinesq force $\mathrm{F}_{\mathrm{b}}$ is incorporated

217 in the model by shifting the velocity field by a term of $F_{b} \tau_{f} / \rho$ as proposed by Shan and Chen [43],

218 where $F_{b}\left(=-\beta g\left(T-T_{0}\right) / \Delta T\right)$. By this treatment, there is no need to add a force term to the

219 collision operator. On the other hand, in g-distribution function, the source term is treated as per

220 the method proposed by Luo [44]. Hence, the resulting force in the LBM frame will be: $S_{h}^{g}=-\omega_{i} S_{h}$

221 with $S_{h}\left(=S t e^{-l} \partial \varepsilon / \partial t\right)$ being the source (or sink) term that handles the phase-change. Note that,

222 we performed tests on the temperature and liquid fraction to insure that they converge within an 223 acceptable tolerance after one iteration for the parameters set considered in this study.

224 It is worth recalling that the description and validation of the model adopted herein can be found in $[21,45,46]$. The numerical model will calculate the temperature and velocity fields for both 
conduction and convection heat transfer modes. Afterwards, the liquid fraction will be calculated

227 from the enthalpy while taking into consideration the impurities' presence. Hence, the enthalpy $\mathrm{h}$ 228 is calculated from equation (4).

229 The liquid fraction $(\mathcal{E})$ is computed as:

$230 \quad \varepsilon= \begin{cases}1 & \text { if } \varepsilon_{1}=1 \\ \varepsilon_{2}(h) & \text { if } \varepsilon_{1}=0\end{cases}$

231 where $\varepsilon_{1}$ is an indicator parameter that is equal to 1 as long as nucleation did not occur for the

232 solidification phase. For nucleation to occur the temperature should fall below the nucleation

233 temperature $T_{n u c}$, where the degree of supercooling is the estimated as $\left(T_{m}-T_{n u c}\right)$. Note that this

234 happens only in solidification, so that the solidification and melting curves are defined according

235 to different indicators. The above numeric indicator controls what enthalpy curve is used for the

236 calculation of liquid fraction according to Fig. 3, and then,

237

$$
\varepsilon_{2}(h)= \begin{cases}0 & \text { for } h<h_{s}=c_{s, p c m} T_{E}=H_{0} \\ \frac{h-h_{s}}{h_{l}-h_{s}} & \text { for } h_{s} \leq h \leq h_{l}=h_{s}+L_{f} \\ 1 & \text { for } h>h_{l}\end{cases}
$$

238 It is useful to recall that, in the current model, the solid and liquid phases are defined according

239 to the liquid fraction value. Therefore, a mushy zone state is assigned when the value of $\varepsilon$ is between

240 zero and one. In this case, the velocity field is partially bounced back and the macroscopic velocity

241 is modified $[15,45,46]$. The procedure for implementing the partial bounce-back approach is

242 described in $[45,46]$.

243 For the velocity field, the non-slip BCs are used for all the cavity walls. These are performed by

244 the on-grid bounce-back (BB) boundary conditions:

245

$$
f_{i}\left(x_{w}, t+1\right)=f_{j}\left(x_{w}, t\right)
$$


$246 x_{w}$ being the fluid node adjacent to the wall, and $i$ and $j$ represent two opposite lattice directions

247 on the boundary site. Note that the BB conditions apply to the DF in non-parallel directions at a 248 solid wall.

249 To specify a constant temperature at the left and right walls, we use the method proposed by 250 Inamuro et al. [47]. Its principle is to substitute unknown DFs for a boundary point with local 251 equilibrium values using an adjusted temperature to set the defined temperature at that point. 252 Specifically, the adjusted temperature on the left side can be expressed as:

253

$$
T^{\prime}=\frac{6}{1-3 v_{w, x}}\left(T_{h}-\sum g_{k}\right)
$$

$254 v_{w, x}$ being the computed near-wall velocity, and $g_{p}$ represents a known distribution function.

255 Hence, the unknown DFs $g_{p}$ are computed by $g_{p}=T^{\prime} \omega_{i}\left(1+\vec{e}_{i} \cdot \vec{U} / c_{s}^{2}\right)$. As for the adiabatic BCs,

256 the Neumann BCs are achieved using the BB boundary conditions for the distribution $g_{i}$, as

257 prescribed for $f_{i}$.

258 In the nearly incompressible formulation, the basic thermo-hydrodynamic properties, such as 259 density $\rho$, momentum density, $\rho U$, and temperature, $T$, are defined as moments of the DFs, $f_{i}$ 260 and $g_{i}$, as follows,

$$
\rho=\sum_{i=0}^{i=8} f_{i}, \quad \rho U=\sum_{i=0}^{i=8} e_{i} f_{i}, \quad T=\sum_{i=0}^{i=8} g_{i}
$$

262 To simulate the presence of a mushy zone (co-existence of liquid and solid), a step is added to 263 mimic the bounce-back at a lattice node [23, 45, 46]. This condition redirects the incoming fluid 264 packets prior to the collision step, as follows:

$$
f_{i}^{o u t}(x, t)=(1-\varepsilon) f_{i}^{c o l}+\varepsilon f_{i}^{i n}(x, t)
$$


where $f_{i}^{\text {in }}$ and $f_{i}^{\text {out }}$ denote the incoming and outgoing fluid packet densities at a node.

267 This ensures that for a completely liquid phase ( $\varepsilon=1)$, a normal collision is conducted.

268 However, when it is completely solid ( $\varepsilon=0$ ), the flow is bounce-backed and blocked, whereas for

269 values between 0 and 1, the flux is partially bounce-backed according to the solid fraction estimated

270 at the node. Such a scheme has been verified in our previous work compared to analytical solutions

271 and other numerical methods [21-23, 40, 41].

272 The velocity field is then modified in the mushy zone and expressed in terms of the in-coming

273 fluid packet densities,

$274 \quad U^{*}=\varepsilon \cdot U$

275 This modified velocity is in accordance with the requirements of the partial bounce-back 276 approach $[23,45,46]$. As a result, the flow in the mushy zone will be dealt as flow in a porous 277 medium and will therefore be governed by Darcy's law as proved by derived analytical solutions $278[23,45,46]$.

\section{4. Experimental Setup}

280 Recall that the main task targeted here is to develop a mutually compatible experimental and 281 numerical method to characterize the studied PCM. The major enhancement in the current 282 numerical model is to add natural convection and supercooling, adopt variable thermo-physical 283 properties, and use the real enthalpy curves corresponding to the considered PCM (viz. 284 Octadecane). Let's point out that this PCM is an alkane hydrocarbon of chemical formula is $285 \mathrm{CH}_{3}\left(\mathrm{CH}_{2}\right)_{16} \mathrm{CH}_{3}$ with Prandtl number is about 50. In general, for high Prandtl values, the 286 momentum diffusivity dominates, and convection seems very efficient in transferring heat 287 (energy).

288 To solve this physical problem, the TLBM, for phase change in multi-layered materials, is used 289 herein. However, before confronting numerical simulations findings, we perform experiments on 
the Octadecane to characterize its main thermo-physical properties: conductivity (solid and liquid),

291 heat capacity (solid and liquid), and latent heat of fusion. The numerical model, hereby, helps us

292 to determine both the real enthalpy curve and the degree of supercooling in the material. Figure 2

293 shows the schema of the experimentally studied sample of Plexiglas containing Octadecane as

294 PCM. Tables 1 and 2 gather the properties of Octadecane and Plexiglas, used in the numerical

295 model, as per the literature $[48,49]$ and verified experimentally with an acceptable tolerance.

296 The experimental setup and its associated equipment, used in this work, are schematically 297 depicted in Figs. 2 and 3(a, b). The studied phase-change material, viz. Octadecane (99\% pure), is 298 placed inside a parallelepiped Plexiglas enclosure and prone to a temperature gradient through 299 exchange plates controlled by two thermo-regulated baths (Julabo Model $34 \mathrm{HE}-1 \mathrm{~kW}$ with a 300 precision of about $\pm 0.01{ }^{\circ} \mathrm{C}$ )) that define thermal conditions (see specifications in [50]). The 301 exchange aluminum plates $(500 \mathrm{~mm} \times 500 \mathrm{~mm} \times 19 \mathrm{~mm})$ allow imposing temperature variations, 302 with respect to selected time scales, on the two dominant faces (left and right faces). The upper and 303 bottom faces, of the studied sample, are insulated by a $14.5 \mathrm{~cm}$-thick polystyrene (a thermally 304 insulating material). Such insulation also serves to minimize the heat transfer from the sample 305 lateral faces into the surrounding medium. This is the guarded hot plate approach principle, often 306 used when characterizing the thermal performance of PCM samples. The flux-meters used herein 307 are "tangential gradients flux meters". The inserted sensors (Captecv, France) on the sample's both 308 sides were pre-calibrated (using the comparative method) with a precision of about $2 \%$, using the 309 device described by [51]. Their surface, thickness and sensitivity are $210 \times 140 \mathrm{~mm}^{2}, 0.2 \mathrm{~mm}$ and $310124 \mu V \cdot W^{-1} \cdot m^{-2}$, respectively. The various sensors are connected to a multichannel multimeter 311 (Keithley 2700) adapted to low level signal measurements. Experimental data are scanned at 312 regular and adjustable time steps of $10 \mathrm{~s}$. The adopted experimental setup permits the simultaneous 313 measurement of heat fluxes and temperatures through the different faces. Note that data acquisition 314 is facilitated by a PC running LabVIEW for further analysis. 
According to the thermal program applied to the sample, it is possible to characterize the

316 apparent thermal conductivity, the specific heat capacity, the phase change temperature and latent

317 heat of the sample. Indeed, the experimental set-up permits to impose temperature loading on each

318 face of the studied sample. Simultaneous measurements of temperatures and heat fluxes exchanged

319 during heating and cooling processes allow the determination of the apparent thermo-physical

320 properties. The characterization also yields to the determination of conductivities and heat

321 capacities when the PCM is in solid or liquid state. During the phase change, temperature and the

322 latent heat can be determined via proven methods [50 - 52], to name few.

\section{5. Obtaining Octadecane thermo-physical properties}

\section{$324 \quad$ 5.1. Thermal conductivity and thermal contact resistance in solid phase}

325 For the solid phase test, we impose, using the previous experimental setup, temperatures of $\mathrm{T}_{\mathrm{G}}$

$326=10{ }^{\circ} \mathrm{C}$ and $\mathrm{T}_{\mathrm{D}}=15^{\circ} \mathrm{C}$ (below melting temperature) on the left and right faces, respectively, until

327 a thermal steady state is reached. The heat fluxes are initially constant. At a particular time, an

328 increase of $5^{\circ} \mathrm{C}$ in temperature is imposed in both thermo-regulated baths linked to the plate heat

329 exchangers. This will induce an increase of temperature in the material, before reaching again a

330 thermal equilibrium. The sample would thus store energy (sensible heat) between these two

331 permanent steady states. A similar experiment is performed to determine the thermal conductivity

332 in the liquid phase. The sample is also subjected to a temperature increase of $5^{\circ} \mathrm{C}$ starting from $\mathrm{T}_{\mathrm{G}}$

$333=30{ }^{\circ} \mathrm{C}$ and $\mathrm{T}_{\mathrm{D}}=35{ }^{\circ} \mathrm{C}$, insuring temperatures higher than the melting temperature of the

334 Octadecane. The subjected thermal loading ramp and the resulting heat fluxes are shown in Fig.

$3354(a, b)$.

336 The thermal conductivity $\lambda$ can be determined depending on the sum of heat fluxes and the 337 temperature difference, using the following relation [53],

$$
\lambda=\sum \varphi L / 2 \Delta T
$$


where $\varphi$ is the heat flux density in $W / m^{2}$ and $L$ is the thickness of the sample.

340 It is useful to mention that the used method involved simultaneous measurements of the heat

341 fluxes and temperatures on both sides of the differentially heated sample. Compared to 342 conventional methods of determining the thermal conductivity in steady state, this method is four 343 times faster [53]. The exact term for the quantity measured is "thermal transmission", which, 344 depending on the material being measured, can have components of convective, radiative and 345 conductive heat transfer; it is commonly referred to as the effective or apparent thermal 346 conductivity.

347 The heat sensor is made of a thin material with a high thermal conductivity (copper). Thermal 348 contact resistance (or contact resistivity) may cause huge errors of thermal conductivity 349 measurements if it is not taken into account. Moreover, when there are two different material layers, 350 a thermal resistance exists on their interface. It is more obvious in the case of two solids. In case of 351 thermal insulation materials (small conductivity) the sample's thermal resistance is large and 352 thermal contact resistance can be neglected. But, in case of higher conductivity materials $(>0.1$ $353 \mathrm{~W} / \mathrm{mK}$ ), the thermal contact resistance becomes significant compared to the sample's thermal 354 resistance and cannot be neglected [54]. Hence, it is important to estimate this effect for accurate 355 results.

356 The resistance of the sample can be defined by:

$357 \quad R_{e q}=2 R_{c}+2 R_{p l}+R_{o c t}$

358 where $R_{c}, R_{p l}$, and $R_{o c t}$, are respectively the thermal resistivity contact, resistance of Plexiglas and 359 Octadecane. We first neglect the thermal contact resistivity. Then,

$$
R_{e q}=\frac{L}{\lambda_{e q}}=\frac{2 L_{p l}}{\lambda_{p l}}+\frac{L_{o c t}}{\lambda_{o c t}}
$$

361 Here, we apply Eq. 18 to calculate the equivalent conductivity of the sample (Plexiglas + 362 Octadecane). The literature properties of Plexiglas are gathered in Table 1, and those for 
363 Octadecane are in Table 2. The resultant conductivity in the solid case is: $\lambda_{e q}=0.167 \mathrm{~W} /(\mathrm{m} . \mathrm{K})$.

364 Hence, by applying Eq. 18, we get $\lambda_{o c t}=0.152 W /(m . K)$. This value is very far from the 365 conductivity of Octadecane reported in the literature $[48,49]$. The error is probably due to ignoring 366 the thermal contact resistivity. As stated before, when testing samples of moderate thermal 367 conductivity $(\lambda \sim 0.1-10 \mathrm{~W} /(\mathrm{m} . \mathrm{K})$ the thermal contact (or interface) resistance must be addressed, 368 otherwise significant errors will result. Since we are not sure about $R_{c}$, we will suppose range of 369 values of $1 / R_{c}=50-100$. Thus, as we change $R_{c}$, we obtain different thermal conductivities of 370 solid Octadecane: $\left(R_{c}=1 / 100 ; \lambda_{\text {oct }}=0.219 \mathrm{~W} /(\mathrm{m} . \mathrm{K}) ;\left(R_{c}=1 / 70 ; \lambda_{\text {oct }}=0.27 \mathrm{~W} /(\mathrm{m} . \mathrm{K}) ;\left(R_{c}=1 / 60\right.\right.\right.$; $\lambda_{\text {oct }}=0.31 \mathrm{~W} /(\mathrm{m} . \mathrm{K}) ;\left(R_{c}=1 / 50 ; \lambda_{\text {oct }}=0.39 \mathrm{~W} /(\mathrm{m} . \mathrm{K})\right.$.

372 From here, we can realize the major impact of considering the thermal contact in calculating the conductivity of Octadecane, which has a relatively moderate conductivity. The estimated values of

$374 \lambda_{o c t}$ are plotted versus $R_{c}$ in Fig 5a. The value in the literature for the conductivity of Octadecane is $\lambda_{\text {oct }}($ solid $)=0.356 \mathrm{~W} /(\mathrm{m} . \mathrm{K})$ which corresponds mostly to around $R_{c}=1 / 60$. It is worth mentioning 376 that the contact resistances here occur between the flux sensors and Plexiglas, and also between 377 Plexiglas and solid PCM. This is applicable for the 4 faces of the enclosure. However, since we take a 2D model, we ignore the effect of resistance on the upper and lower faces.

\subsection{Thermal conductivity, thermal contact resistance and convection in liquid phase}

As in the previous procedure, we calculate the conductivity in liquid Octadecane. The Flux 381 density and surface temperatures are plotted in Fig 4b. The estimated value by Eq. 18 is $\lambda_{\text {app }}$ (liquid) $382=0.22 \mathrm{~W} /(\mathrm{m} . \mathrm{K})$, which can be seen as an apparent conductivity. It is important to recall here that 383 the quantity measured may have a convection component. Therefore, we seek to, theoretically, 384 prove the existence of convection in the liquid state. This would check the high value of the 385 apparent conductivity in liquid phase, and then to confirm this experimentally and numerically. 
We need to calculate $R a_{H}=\beta g \Delta T H^{3} / \alpha v$ for the above problem $(A=H / L \approx 20)$, corresponding to the considered sample. This gives us an idea about the mechanism of heat transfer, within the sample, and on the effect of the fluid flow, following the scaling laws [55]. In such a tall enclosure 390 the convection is usually ignored. Here, our aim is to check the importance of considering 391 convection theoretically, numerically, and experimentally.

392 According to the scaling laws [55], the parameter $R a_{H}$ needs to be calculated and to $H / L$ :

$$
\left(R a_{H}\right)^{1 / 4}=\left(\beta g \Delta T H^{3} / v \alpha\right)^{1 / 4}=\left(1.415 \times 10^{10}\right)^{1 / 4} \approx 345 .
$$

$$
\left(R a_{H}\right)^{-1 / 4}=\left(\beta g \Delta T H^{3} / v \alpha\right)^{-1 / 4}=\left(1.415 \times 10^{10}\right)^{-1 / 4} \approx 0.003
$$

$$
H / L=20.2 \text {, so }\left(R a_{H}\right)^{-1 / 4}<H / L<\left(R a_{H}\right)^{1 / 4} .
$$

So, the flow pattern is expected to show a boundary layer on all four walls, with one core remaining stagnant. The dominant heat transfer mechanism is "boundary layer convection" with a significant effect of the fluid flow. To calculate the Nusselt number, we can use an adequate empirical formula. Since $R a_{L}=\beta g \Delta T H^{3} / v \alpha=3.43 \times 10^{5}$, with $10<H / L<40,1<P r<2 \times 10^{4}, 10^{4}$ $400<R a_{L}<10^{7}$, then:

$$
\overline{N u}_{L}=0.42 x \operatorname{Ra}_{L}^{1 / 4} x \operatorname{Pr}^{0.012} x(H / L)^{-0.3}
$$

This relationship allows to deduce $\overline{N u}_{L}=4.33$ with $R a_{L}=\beta g \Delta T L^{3} / v \alpha$. This reveals that the convective heat transfer is four times stronger than the conductive one. Once again, this shows that

404 the convection is the dominant mechanism in this problem. The apparent conductivity measured 405 by Eq. 18 has a convection contribution, and we can state that it is not the equivalent conductivity 406 of the sample.

\section{- Experimental investigation of the convection}

To achieve this, we perform a new experiment. We inject in the Plexiglas enclosure of 409 Octadecane, described in Fig. 2, silver coated hollow glass spheres, and allow them to settle down. 410 Using Particle Image Velocimetry (PIV) system, we trace the flow of the particles inside the 411 enclosure. In the case of liquid Octadecane, due to the presence of convection, and as expected, the 
412 powder circulates inside liquid Octadecane. In contrary, if conduction was the dominant mode, the

413 powder would have stayed at the bottom, and no motion would have been noticed.

414 After proving the presence of convection, we will estimate the value of the conductivity of liquid

415 Octadecane, by the aid of the numerical simulations.

- Numerical assessment of the convection

417 The implemented LBM numerical model is used to evaluate the convection in liquid Octadecane

418 within the Plexiglas enclosure. Thus, the average Nusselt number $\left(\overline{N u}_{L}\right)$ value on the Octadecane

419 interface is 4.81 . Such a value seems close to that estimated empirically by the order of $10 \%$.

420 The average equivalent conductivity for natural convection can be estimated via the following

421 relationship [55]:

422

$$
\frac{\lambda_{a p p}}{\lambda_{e q}} \approx \frac{Q_{L B M, c o n v}}{Q_{L B M, \text { cond }}}
$$

423 where $\lambda_{a p p}$ and $\lambda_{e q}$ are the apparent and equivalent conductivities of liquid Octadecane. Note that,

424 by apparent here, we mean that it contains the convection contribution. As for the equivalent, we 425 point to the conductivity calculated for the sample (Plexiglas + Octadecane). To compute the ratio, 426 we implement two models. The first is for convection (with a Boussinesq force evaluated by the 427 corresponding $R a$ value), and the second is a pure conduction model (without the Boussinesq force, 428 insuring a zero-velocity field). The simulation results do not depend on the selected value of 429 conductivity, since in LBM we assign a fixed Prandtl number of 50. The main aim here is to 430 evaluate the effect of including the Boussinesq force that designates the convection. This method 431 is only an approximation. The calculated ratio is $\lambda_{a p p} / \lambda_{e q}=1.76$, hence the value of the equivalent 432 conductivity is $\lambda_{e q}=0.125 \mathrm{~W} / \mathrm{mK}$. Here, the thermal contact resistance occurs only between the 433 flux sensors and the Plexiglas. Now we use Eq. 18 with different trials on the thermal contact 434 resistance to get: $R_{c}=1 / 100 ; \lambda_{\text {oct }}=0.123 \mathrm{~W} /(\mathrm{m} . \mathrm{K}) ; R_{c}=1 / 70, \lambda_{\text {oct }}=0.137 \mathrm{~W} /(\mathrm{m} . \mathrm{K}) ; R_{c}=1 / 60$; $\lambda_{o c t}=0.151 \mathrm{~W} /(m . K) ; R_{c}=1 / 50 ; \lambda_{o c t}=0.162 \mathrm{~W} /(m . K)$. 
The conductivity of liquid Octadecane is $\lambda_{o c t}=0.148 \mathrm{~W} /(\mathrm{m} . \mathrm{K})$ in literature. So in both liquid

437 and solid cases the closest calculated value of conductivity is obtained when considering $R_{c}=1 / 60$.

438 Fig. $5 \mathrm{~b}$ shows the estimated values of $\lambda_{\text {oct }}$ for the liquid Octadecane versus the thermal contact

439 resistance. As deduced, the effect of thermal resistivity contact is much more in the case of the

440 solid state, where there is a solid-solid contact. Thereby an interface of the air gap may rise in

441 between. From our approach, the conductivity of solid and liquid Octadecane are $\lambda_{\text {oct }}($ solid $)=0.31$

$442 W /(m . K)$ and $\lambda_{\text {oct }}$ (liquid) $=0.151 \mathrm{~W} /(\mathrm{m} . K)$, respectively with $R_{c}=1 / 60$. However, we should still

443 consider border effects for more accuracy.

\section{$444 \quad$ 5.3. Specific heat capacity}

445 The temperatures and the heat fluxes evolution on both sides of the sample, when Octadecane 446 is in the solid and the liquid phases are represented in Fig. 4. A symmetrical behavior of heat fluxes 447 and temperatures measured on both faces of the sample can be observed, which correspond to the 448 results classically obtained with a solid material without phase change.

449 Initially, the sample is isothermal (at a thermal equilibrium state), and then a temperature change 450 is imposed on its both sides. This induces a thermal evolution of the system in an asymptotic way 451 towards a second thermal steady state. Also, it should be noted that the heat fluxes evolve quickly 452 when the temperatures of the sample are increased and then converge to a second thermal 453 equilibrium state obtained at the end of the test. The specific heat capacities of the sample are 454 obtained starting from the determination of the sensible heat accumulated by the material between 455 the imposed temperatures. The sensible heat is calculated by integrating the difference in heat 456 fluxes between the initial and the final state using the following relationship:

$$
Q=\frac{1}{\rho L} \int_{T_{\text {init }}}^{T_{\text {end }}} \Delta \varphi=\sum_{i} C_{p, i}\left(T_{\text {end }}-T_{\text {init }}\right)
$$

458 where $\Delta \varphi$ represents the cumulative heat rate entering the sample and $C_{p}$ is the apparent specific 459 heat capacity $\left(\mathrm{kJ} /\left(\mathrm{kg} .{ }^{\circ} \mathrm{C}\right)\right)$. 
460 The calculated specific heat capacity of Octadecane in solid and liquid phases are: $c_{\text {oct } \text { solid }}=1925$

$461 \mathrm{~kJ} /\left(\mathrm{kg} .{ }^{\circ} \mathrm{C}\right)$ and $c_{o c t, l i q u i d}=2365 \mathrm{~kJ} /\left(\mathrm{kg} .{ }^{\circ} \mathrm{C}\right)$. It is noted that these values are consistent with those 462 available in the literature.

$463 \quad$ 5.4. Analysis of the heat flux with phase-change

464 To analyze the heat flux in the presence of a phase change, we use a four-hour ramp. The sample 465 is initially at $15.8{ }^{\circ} \mathrm{C}$, then the both plates' temperature $T_{p}$ is increased from $15.8{ }^{\circ} \mathrm{C}$ to $40{ }^{\circ} \mathrm{C}$ in 4 466 hours (4h). Then a constant loading of $40{ }^{\circ} \mathrm{C}$ is applied followed by a decreasing ramp until 467 reaching $15.8{ }^{\circ} \mathrm{C}$ again, as illustrated in Fig. 6. As noted, the sample is initially in thermal 468 equilibrium, where the heat flux is zero. This is followed by sensible heat flow when the PCM is 469 still in its solid state. The curve then starts increasing gradually at a time corresponding to the onset 470 of melting. The latent heat absorbed also increases gradually and the largest quantity is absorbed 471 in the vicinity of the melting point. After complete melting, and reaching the constant heating 472 phase, the PCM goes back to a thermal equilibrium, with no more flux variation, until the cooling 473 ramp starts.

474 When cooling starts, the liquid PCM releases sensible heat until reaching the solidification 475 temperature. The difference between the melting and solidification is that the majority of freezing 476 happens directly, and the largest amount of latent heat is released at first, then the rest will solidify 477 gradually. This behavior can be also regarded to the expected shape of the enthalpy curve. The 478 portion around the curve at the solidification temperature is discontinuous. There is a direct energy 479 jump from a temperature point in the liquid state to the solidification point. We note also the 480 existence of supercooling, which is illustrated by the formation of a vertical portion or discontinuity 481 in the curve (Fig. 1). After complete freezing, the PCM returns back to its equilibrium state with 482 almost zero flux.

484 As previously stated, the major aim is to first estimate the main thermo-physical properties and 
to highlight their effect on the numerical results if the supercooling, convection, and soluble

486 impurities are ignored or not. To achieve this, we compare the numerical results, using an improved

487 model, with the experimental ones. The properties in Tables 1 and 2 and the verified thermo-

488 physical properties (conductivities, specific heat capacities, latent heat of fusion, thermal contact

489 resistance, etc.) are fixed in the model. It should be noted that the Boussinesq force has been varied

490 to account for convection, the melting temperature to calibrate the enthalpy curve, and the degree

491 of supercooling to estimate the nucleation temperature. In the following, some significant results

492 showing effects of physical phenomena are comprehensively presented and discussed.

\section{6.1. Effect of enthalpy curve shape}

494 As explained before, the presence of soluble impurities in the PCM results in a melting temperature depression. Recall that, the used Octadecane is thought to be $99 \%$ pure. So, the $1 \%$ of soluble impurities can have an impact on the heat flux curve. This will be investigated theoretically and numerically. First, the depression in the melting temperature is calculated from Eq. (1) to obtain

$498 T_{m}=28.03{ }^{\circ} \mathrm{C}$. Thus, the PCM melts with a depression of about $0.1{ }^{\circ} \mathrm{C}$ compared to the case of 499 pure Octadecane. Then, this melting temperature will be used in the numerical model, to check if 500 this the numerical and experimental fluxes match. If not, $T_{m}$ will be changed until they well match.

501 The enthalpy-temperature curves are plotted in Fig. 7 for different values of $\left(T_{a}-T_{m}\right)$. As 502 demonstrated, the curve becomes less steep as $T_{m}$ deviates from $T_{a}$. This induces a melting 503 temperature range that causes a gradual increase in latent heat instead of absorbing it at once.

504 Moreover, to show the important impact of enthalpy curve on the flux, we compare the heat flux 505 obtained numerically for the case pure Octadecane to the experimental one (cf. Fig. 8a). In pure 506 PCM, there is no melting range. Thus, the immediate absorption of latent heat at the melting 507 temperature results in a sharp and high rate of heat flow at this moment, as shown in the comparison 508 curves. However, when there exists a temperature depression, the rate of heat absorption decreases 509 more, since there is no instant absorption and release. The accurate prediction of the onset of 
melting and freeing is highly dependent on taking into account the real enthalpy-temperature

511 relation.

512 By comparing the experimental and numerical curves, the best fit was obtained for $T_{m}=27.6$

$513{ }^{\circ} \mathrm{C}$, which corresponds to a variation of about $0.5^{\circ} \mathrm{C}$ from the supposed pure melting temperature

514 found in literature (Fig. 7). This shows that using Eq. (1) may not be adequate in our case but can

515 be used as pre-estimation. Also, the supposed melting temperature $[48,49]$ of pure Octadecane is

516 also questionable. If Octadecane is considered pure, the heat flux curve will show a high

517 discrepancy when compared to the experimental one, as shown in Fig. 8a. The curve obtained

518 numerically comes from considering the enthalpy curve as the traditional piece-wise function. This

519 shows that such a curve cannot be used for our case.

520 The final numerical curve for melting is plotted in Fig. 11 despite the fact that this is the result

521 from the enhanced numerical model, i.e. including also convection. In addition, we highlight that

522 the heating rate does not influence the prediction of the melting point $T_{m}$, since the enthalpy curve

523 is unique for a material.

\section{$524 \quad 6.2$. Effect of presence of supercooling and convection}

525 We show, in what follows, the discrepancy that would have resulted if we ignored the presence 526 of convection and supercooling. The major effect of ignoring convection (cf. Fig. 9a) is on 527 estimating the time of melting and mainly that of solidification. At first, the material is solid. So 528 convection will start affecting the curve as soon as the liquid fraction starts increasing. It is 529 important here to address the effectiveness of our partial bounce-back LBM model. By this method, 530 we are able to treat the mushy zone as a porous medium, where the velocity of the fluid is restrained 531 but not completely blocked. The Rayleigh number ( $\mathrm{Ra})$, corresponding to the real convection, is 532 searched by a fitting method, and is found to be $\mathrm{Ra}=1.2 \times 10^{4}$. Higher values would lead to an over 533 estimation (Fig. 9b).

534 On the other hand, if supercooling is ignored (see Fig. 10a), the solidification starts before the real instant. So, the experimental and numerical results will show a lag in time. To overcome this, 
536 we have sought the degree of supercooling through a tuning (fitting) method. Hereafter, the best

537 estimated degree of supercooling corresponds to $1.4^{\circ} \mathrm{C}$. If higher supercooling degree is used, the

538 supercooling phenomenon will be overestimated (see Fig. 10b).

539 By this, we can combine all the enhancements to the present model: using the real enthalpy

540 curve, including convection and supercooling, using variable thermo-physical properties for solid

541 and liquid phases, and using a partial bounce-back LBM for phase change to better simulate the

542 low effect of convection. The enhanced model calculated for $\mathrm{Ra}=1.2 \times 10^{4}$, degree of super cooling

543 of $1.4{ }^{\circ} \mathrm{C}$, and a melting point depression of $0.43{ }^{\circ} \mathrm{C}$ is displayed in Fig. 11 , and shows a great

544 improvement, and matches the experimental results.

545 The simplifications taken in some numerical models can result in an overall discrepancy in the

546 real behavior of PCM. These discrepancies may lead to wrong estimation of the fusion times and

547 the energy amount stored. Consequently, the PCM will not give the desired performance. The major

548 enhancement to the proposed model was to take into account natural convection, supercooling, to

549 adopt variable thermo-physical properties for solid and liquid phases, and to use the real enthalpy

550 curves corresponding to the considered PCM. These improvements have led to better agreement

551 with the experimental results, and showed that if the above phenomena were present, they cannot

552 be ignored.

\section{7. Conclusion}

554 The main aim of this work is to characterize the thermo-physical properties and performance of

555 Octadecane. This PCM may be promising for the usage in glass facades or other building materials

556 and latent heat systems. To achieve such an objective, we adopted an approach based on

557 experimental and numerical techniques. The enhanced numerical model, used here, can help

558 estimate some properties, and can be also used as an optimization tool for any practical application.

559 The thermo-physical properties obtained experimentally and, using the numerical model, match

560 the expected values from literature. The adopted numerical model is a thermal LBM with a partial 
561 bounce-back approach and an enthalpy-based model. We considered the natural convection,

562 supercooling, variable thermo-physical properties (when necessary), and the real enthalpy curve of

563 Octadecane. Simulations performed using the improved model corroborate the experimental results

564 and show that ignoring these phenomena may lead to wrong estimation of the fusion times and

565 amount of energy stored and the PCM will not give the desired performance.

\section{Disclosure statement}

567 The authors declare no potential conflicts of interest regarding authorship and/or publication of this 568 paper.

\section{ORCIDs iD}

570 Alissar Yehya https://orcid.org/0000-0001-9956-3636

571 Hassane Naji http://orcid.org/0000-0002-5994-7958

572 Laurent Zalewski https://orcid.org/0000-0002-7298-3224

\section{References}

574 [1] M. Hegger, M. Fuchs, T. Stark, and M. Zeumer, Energy Manual, Sustainable architecture. $575 \quad$ Edition Detail 2008, ISBN-10: 3764388307.

576 [2] Energy Efficiency Requirements in Building Codes, Energy Efficiency Policies for New 577 Buildings, International Energy Agency, 2008.

578 [3] A. Castell, M. Medrano, J. Roca, A. Vila A, and L.F. Cabeza, Experimental Study of PCM in 579 Mediterranean Buildings, Effstock 2009 Conference, Stockton University, 2009.

580 [4] A. Sharma, V.V. Tyagi, C.R. Chen, and D. Buddhi, Review on thermal energy storage with 581 phase change materials and applications. Renew. Sust. Energy Rev., vol. 13, pp. 318-345, $582 \quad 2009$.

583 [5] N. Soaresa, J. J. Costab, A. R. Gaspar, and P. Santos P, Review of passive PCM latent heat 584 thermal energy storage systems towards buildings' energy efficiency, Energy Build., vol. 59, $585 \quad$ pp. 82-103, 2013. 
586

[6] R. Baetens, B. P. Jelle, and A. Gustavsen, Phase change materials for building applications: a state-of-the-art review, Energy Build., vol. 42, pp. 1361-1368, 2010.

[7] B. Zalba, J. M. Marín, L. F. Cabeza, and H. Mehling, Review on thermal energy storage with phase change materials: Heat transfer analysis and applications, Appl. Therm. Eng., vol. 23, pp. 51-83, 2003.

[8] M. M. Farid, A. M. Khudhair, S. A. K. Razack, and S. Al-Hallaj, A review on phase change energy storage: materials and applications, Energy Convers. Manage., vol. 45, pp. 1597-1615, 2004.

[9] Y. Zhang, G. Zhou, K. Lin, Q. Zhang, and H. Di, Application of latent heat thermal energy storage in buildings: State of the art and outlook, Build. and Environ., vol. 42, pp. 2197-2209, 2007.

[10] Y. Dutil, D. Rousse, N. Ben Salah, S. Lassue, and L. Zalewski, A review on phase-change materials: Mathematical modeling and simulations, Renew. Sust. Energy Rev., vol. 15, pp. 112-130, 2011.

[11] V. R. Voller, C. R. Swaminathan, and B. G. Thomas, Fixed grid techniques for phase change problems: a review. Int. J. Numer. Methods Eng., vol. 30, pp. 875-898, 1990.

[12] R.E. White, An enthalpy formulation of the Stefan problem, SIAM J. Numer. Analysis, vol. 19, pp. 1129-57, 1982.

[13] C. Bonacina, G. Comini, A. Fasano, and M. Primicerio, Numerical solution of phase-change problems. Int. J. Heat Mass Transfer, vol. 16, pp. 1825-32, 1973.

[14] X. Zeng and A. Faghri, Temperature-transforming model for binary solid-liquid phasechange problems, Part I: Mathematical modeling and numerical methodology, Numer. Heat Transfer, Part B, vol. 25, pp. 467-80, 1994.

[15] F. Talati and M. Taghilou, Lattice Boltzmann application on the PCM solidification within a rectangular finned container, Appl. Therm. Eng., vol. 83, pp. 108-120, 2015. 
611 [16] M. Taghilou and F. Talati, Numerical investigation on the natural convection effects in the melting process of PCM in a finned container using lattice Boltzmann, Int. J. Refrigeration, vol. 70, pp. 157-170, 2016.

614 [17] A. R. Darzi, M. Jourabian, and M. Farhadi, Melting and solidification of PCM enhanced by radial conductive fins and nanoparticles in cylindrical annulus, Energy Convers. Manage., vol.118, pp. 253-263, 2016.

[18] Y. Su and J. H. Davidson A new mesoscopic scale timestep adjustable non-dimensional lattice Boltzmann method for melting and solidification heat, Int. J. Heat Mass Transfer, vol.

[19] M. Jourabian and M. Farhadi, Melting of nanoparticles-enhanced phase change material (NEPCM) in vertical semicircle enclosure: numerical study, J. Mech. Sci. Technology, vol. 29, no. 9, pp. 1-12, 2015.

[20] M. Jourabian, M. Farhadi, and K. Sedighi, On the expedited melting of phase change material (PCM) through dispersion of nanoparticles in the thermal storage unit, Comput. Math. Appl., vol. 67, pp. 1358-1372, 2014.

[21] A. Yehya and H. Naji, Thermal lattice Boltzmann simulation of entropy generation within a square enclosure for sensible and latent heat transfers, Appl. Sci., vol. 5, pp. 1904-1921,

[23] A. Yehya and H. Naji, Towards the simulation of supercooling and convection in phase 2015.

[22] A. Yehya, H. Naji, L. Zalewski, Assessment of a Lattice Boltzmann Model to simulate fluid flows with complex geometries, Computational Thermal Sciences, vol. 7 (2), 2015.

634 [23] Q. Li, K. H. Luo, Q. J. Kang, Y. L. He, Q. Chen, and Q. Liu, Lattice Boltzmann methods for multiphase flow and phase-change heat transfer, Progress Energy Comb. Sci., vol. 52, pp. 62-105, 2016. 
637 [24] V. R. Voller, Fast implicit finite-difference method for the analysis of phase change 638 problems, Numer. Heat Transfer, Part B, vol. 17, pp. 155-69, 1990.

639 [25] C. R. Swaminathan and V. R. Voller, Towards a general numerical scheme for solidification systems, Int. J. Heat Mass Transfer, vol. 40, pp. 2859-68, 1997.

[26] D. Chatterjee, Lattice Boltzmann Modeling for Melting/Solidification Processes, In book: Hydrodynamics - Optimizing Methods and Tools, Harry Schulz et al. (Eds.), ISBN: 978-953307-712-3, InTechopen, 2011. doi: 10.5772/28236

644 [27] S. N. AL-Saadi and Z. J. Zhai, Modeling phase change materials embedded in building enclosure: A review. Renew. Sust. Energy Rev., vol. 21, pp. 659-673, 2013.

[28] M. Morgan, R. W. Lewis, and O. C. Zienkiewicz, An improved algorithm for heat conduction problems with phase change, Int. J. Numer. Methods Eng., vol.12, pp. 1191-1195, 1978.

[29] C. Huber, A. Parmigiani, B. Chopard, M. Manga, and O. Bachmann, Lattice Boltzmann model for melting with natural convection, Int. J. Heat Fluid Flow, vol. 29, pp. 1469-1480, 2008.

[30] M. Jourabian, M. Farhadi, and A. A. R. Darzi, Convection-dominated melting of phase change material in partially heated cavity: lattice Boltzmann study, Heat Mass Transfer, vol. 49, pp. 555-565, 2013. $3507,2010$.

[32] S. Chen and G.D. Doolen, Lattice Boltzmann Method for Fluid Flows, Annu. Rev. Fluid

[34] A. Xu, L. Shi, T.S. Zhao, Accelerated lattice Boltzmann simulation using GPU and OpenACC with data management, Int. J. Heat Mass Transfer, vol. 109, 577-588, 2017. 
663

664

665

666

667

668

669

670

671

672

673

674

675

676

677

678

679

680

681

682

683

684

685

686

[35] D. Gao and Z. Chen, Lattice Boltzmann simulation of natural convection dominated melting in a rectangular cavity filled with porous media, Int. J. Therm. Sci., vol. 50, 493-501, 2011.

[36] D. Gao, Z. Chen, L. Chen, A thermal lattice Boltzmann model for natural convection in porous media under local thermal non-equilibrium conditions, Int. J. Heat Mass Transfer, vol. 70, 979-989, 2014.

[37] C. K. Schoff and R. L. Blaine, Purity determinations by thermal methods, STP 838, ASTM International (ed.), 1984.

[38] E. Franquet, S. Gibout, P. Tittelein, L. Zalewski, and J.-P. Dumas, Experimental and theoretical analysis of a cement mortar containing microencapsulated PCM, Appl. Therm. Eng., vol. 73, no. 1, pp. 32-40, 2014.

[39] S. Gibout, E. Franquet, J.-P. Bédécarrats, and J. -P. Dumas, Comparison of different modelings of pure substances during melting in a DSC experiment, Thermochim. Acta, vol. 528, pp. 1-8, 2012.

[40] J. -P. Dumas, S. Gibout, P. Cézac, E. Franquet, and D. Haillot, Model for the DSC thermograms of the melting of ideal binary solutions, Thermochim. Acta, vol. 57, pp. 64-76, 2013.

[41] S. Chapman and T. Cowling, The mathematical theory of non-uniform Gases, $3^{\text {th }}$ ed., Cambridge University Press, Cambridge, 1970.

[42] Z. Guo, B. Shi, and C. Zheng, A coupled lattice BGK model for the Boussinesq equations, Int. J. Numer. Methods Fluids, vol. 39, no. 4, pp. 325-342, 2002.

[43] H. Chen and X. Shan, Simulation of nonideal gases and gas-liquid phase transitions by the lattice Boltzmann equation. Phys. Rev. E, vol. 49, pp. 2941-2948, 1994.

[44] L. -S. Luo, Lattice-Gas automata and lattice Boltzmann equations for two-Dimensional hydrodynamics, PhD Thesis, Georgia Institute of Technology, Atlanta, GA 30332, 1993. 
687

[45] A. Yehya, H. Naji, and M. C. Sukop, Simulating flows in multi-layered and spatially-variable permeability media via a new gray lattice Boltzmann model, Comp. Geotech., vol. 70, pp. 150-158, 2015.

[46] A. Yehya, Contribution to the experimental and numerical characterization of phase change materials: Consideration of convection, supercooling, and soluble impurities, $\mathrm{PhD}$ Thesis Univ. Artois/Applied Sciences' Faculty, F-62400 Béthune, France, 2015.

[47] T. Inamuro, M. Yoshino, H. Inoue, R. Mizuno, and F. A. Ogino, Lattice Boltzmann method for a binary miscible fluid mixture and its application to a heat-transfer problem. J. Comput. Phys., vol. 179, pp. 201-215, 2002.

[48] J. F. Messerly, G. B. Guthrie, S. S.Todd, and H. L. Finke, Low-temperature thermal data for pentane, n-heptadecane, and n-octadecane. Revised thermodynamic functions for the nalkanes, C5-C18, J. Chem. Eng. Data, vol. 12, no., pp. 338-346, 1967.

[49] H. Mehling and L. F. Cabeza, Heat and cold storage with PCM: An up to date introduction into basics and applications, Springer-Verlag, Berlin-Heidelberg, 2008.

[50] A. Joulin, L. Zalewski, S. Lassue, and H. Naji, Experimental investigation of thermal characteristics of a mortar with or without a micro-encapsulated phase change material. Appl. Therm. Eng., vol. 66, pp. 171-180, 2014.

[51] A. Joulin, Z. Younsi, L. Zalewski, S. Lassue, D. R. Rousse, and J. P Cavrot, Experimental and numerical investigation of a phase change material: thermal-energy storage and release, Appl. Energy, vol. 88, pp. 2454: 2462, 2011.

[52] M. Lachheb, Z. Younsi, H. Naji, M. Karkri, and S. Ben Nasrallah, Thermal behavior of a hybrid PCM/plaster: A numerical and experimental investigation”, Appl. Therm. Eng., vol. 111, pp. 49-59, 2017. 
710 [53] L. Zalewski, S. Lassue, D. R. Rousse, A. Joulin, Z. Younsi, A novel technique for 711 experimental thermophysical characterization of phase-change materials, Int. J. Thermophys, $712 \quad$ vol. 32, pp. 674-692, 2010.

713 [54] A. Tleoubaev A. and Brzezinski, Fast measurements of absolute thermal conductivity 714 excluding thermal contact resistance errors, LaserComp, Inc., 20 Spring Street, Saugus, $715 \quad$ Massachusetts 01906, USA.

716 [55] A. Faghri, Y. Zhang, and J. R. Howell, Advanced Heat and Mass Transfer, Global Digital $717 \quad$ Press, 2010. 


\section{$719 \quad$ List of Tables}

720 Table 1. Properties of Plexiglas $[48,49]$

\begin{tabular}{ll}
\hline Property & Value \\
\hline Heat capacity & $1470 \mathrm{~J} . \mathrm{Kg}^{-1} \cdot \mathrm{K}^{-1}$ \\
Thermal conductivity & $0.19 \mathrm{~W} .(\mathrm{m} . \mathrm{K})^{-1}$ \\
Density & $1190 \mathrm{Kg} \cdot \mathrm{m}^{-3}$ \\
\hline
\end{tabular}

721

722 Table 2. Properties of Octadecane from literature [48, 49]

\begin{tabular}{ll}
\hline Property & Value \\
\hline $\mathrm{c}_{\text {solid }}$ & $1910 \mathrm{JKg}^{-1}{ }^{\circ} \mathrm{C}^{-1}$ \\
$c_{\text {liquid }}$ & $2230 \mathrm{JKg}^{-1} \mathrm{C}^{-1}$ \\
Density $\rho$ & $779 \mathrm{Kgm}^{-3}$ \\
$\lambda_{\text {solid }}$ & $0.356 \mathrm{Wm}^{\circ} \mathrm{C}^{-1}$ \\
$\lambda_{\text {liquid }}$ & $0.149 \mathrm{Wm}^{\circ} \mathrm{C}^{-1}$ \\
Enthalpy of fusion & $241650 \mathrm{JKg}^{-1}$ \\
Temperature of fusion & $28.15^{\circ} \mathrm{C}$ \\
$\beta$ & $0.02 \mathrm{~K}^{-1}$ \\
$\operatorname{Pr}$ & 50 \\
\hline
\end{tabular}


726 Figure 1. Enthalpy-temperature relationship for pure PCMs with soluble impurities in the presence of supercooling.

728 Figure 2. Two-dimensional schematic of the studied sample.

729 Figure 3. (a) Schematic illustration of the experimental setup, (b) Schematic illustration of the 730 studied sample.

731 Figure 4. Heat flux curves with no phase-change for (a) solid state, (b) liquid state.

732 Figure 5. Estimated thermal conductivity vs thermal contact resistivity: (a) solid state, (b) liquid state.

734 Figure 6. Heat flux curves indicating the presence of supercooling.

735 Figure 7. Enthalpy-temperature relationship for different $\left(\mathrm{T}_{\mathrm{a}}-\mathrm{T}_{\mathrm{m}}\right)$ values.

736 Figure 8. (a) Effect of the presence of impurities on the heat flux, (b) Numerical and experimental 737 shapes with $\mathrm{T}_{\mathrm{m}}=27.6^{\circ} \mathrm{C}$.

738 Figure 9. Effect of convection on the shape of the heat flux curve: (a) ignoring convection, (b) 739 overestimating convection

740 Figure 10. Effect of supercooling on the shape of the heat flux curve: (a) ignoring supercooling, 741 (b) overestimating supercooling

742 Figure 11. Experimental vs. numerical results when using the enhanced model. 


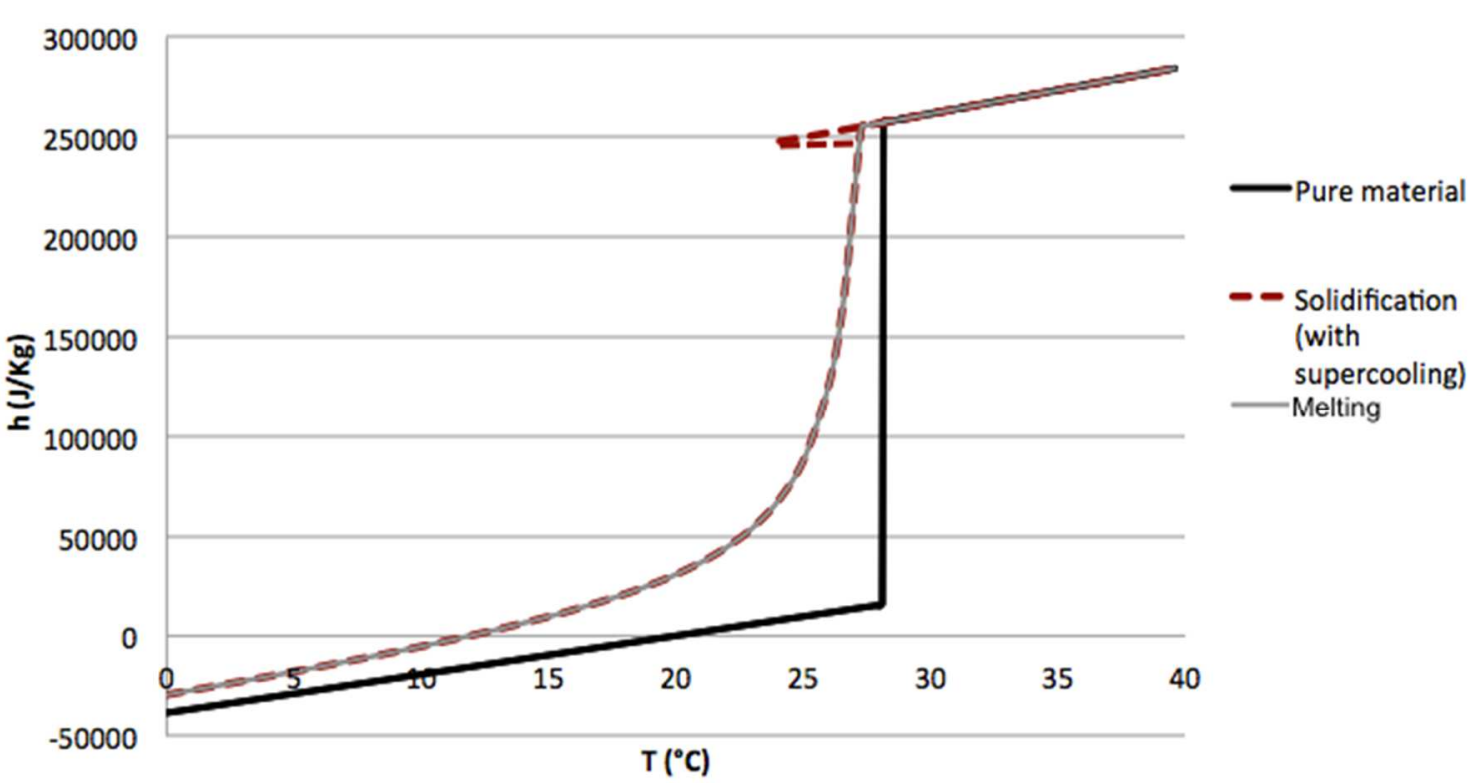

Figure 1. Enthalpy-temperature relationship for pure PCMs with soluble impurities in the presence of supercooling

752

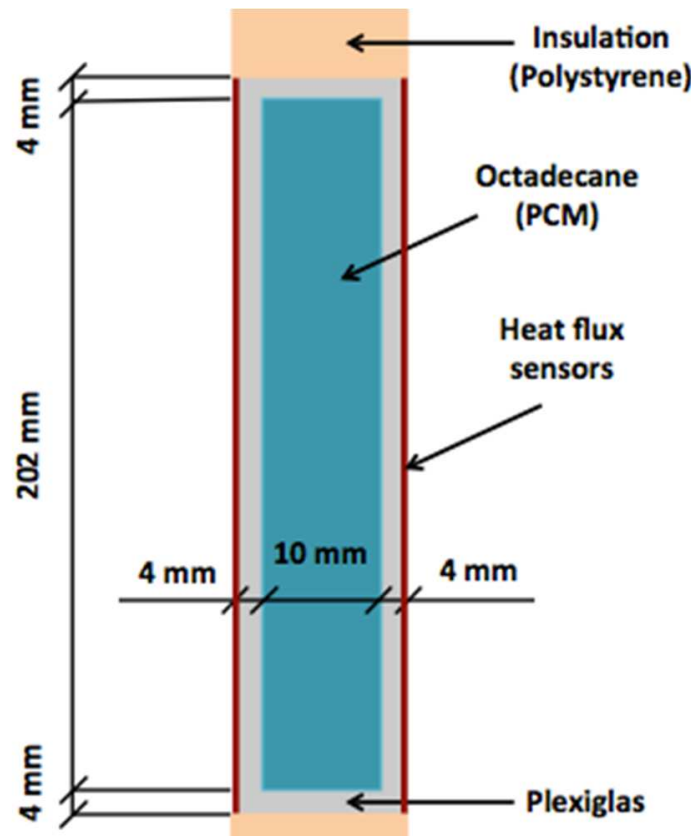

Figure 2. Two-dimensional schematic of the studied sample 


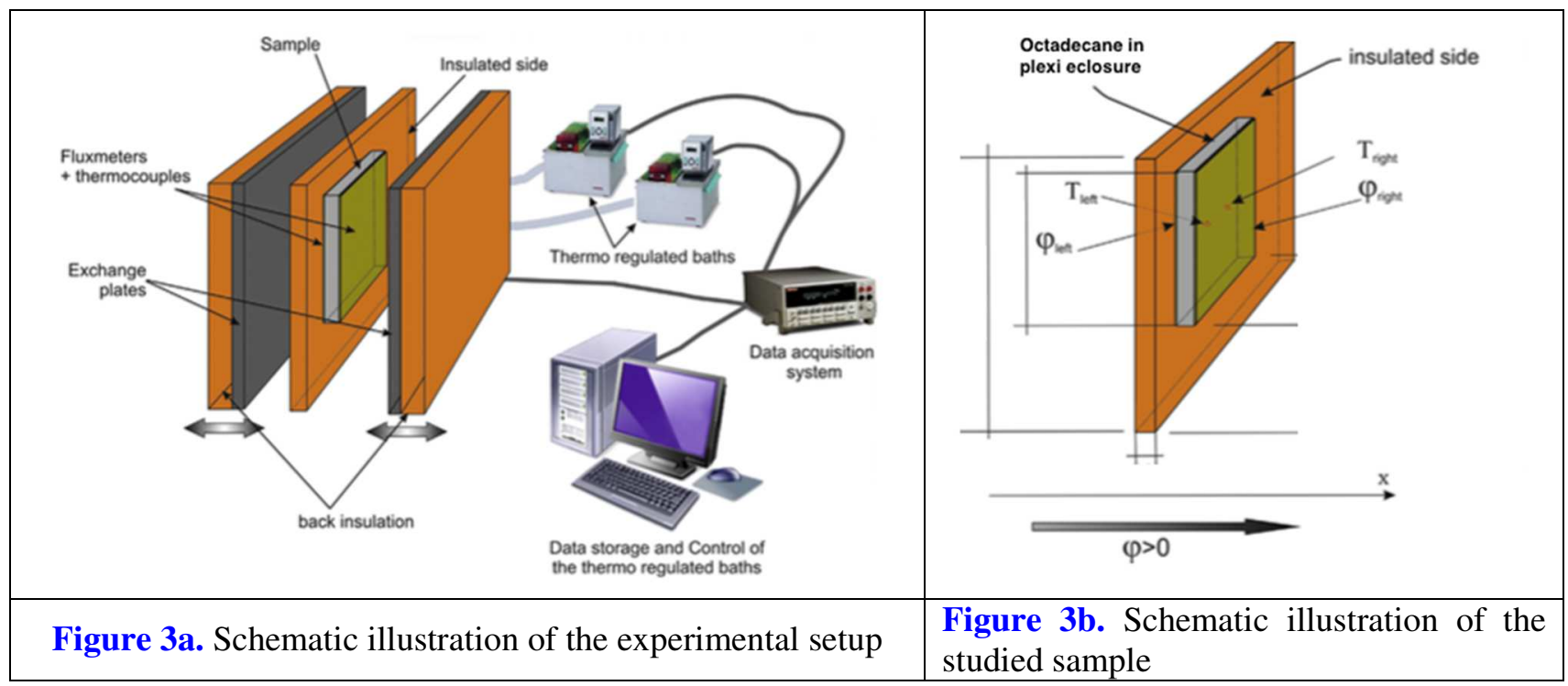

761

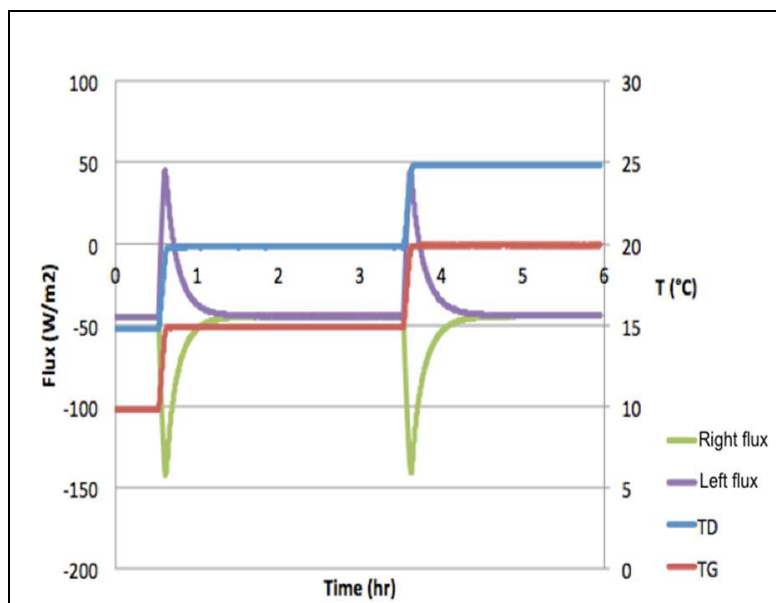

(a)

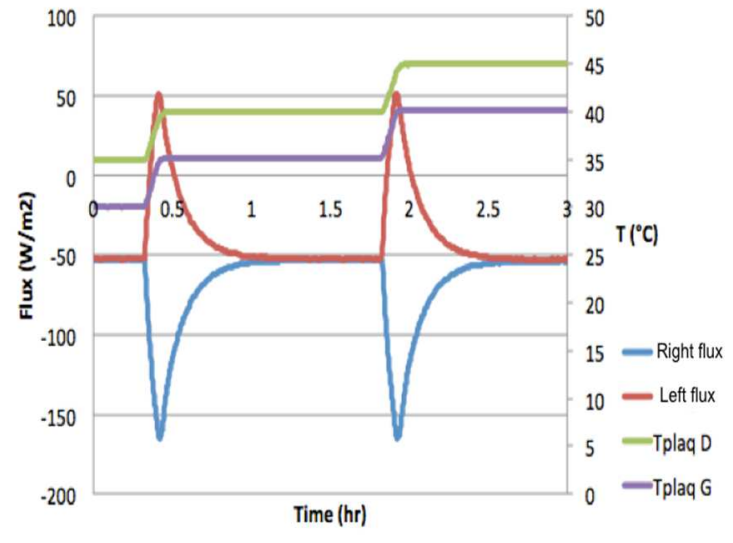

(b)

762

Figure 4. Heat flux curves with no phase-change for (a) solid state, (b) liquid state.

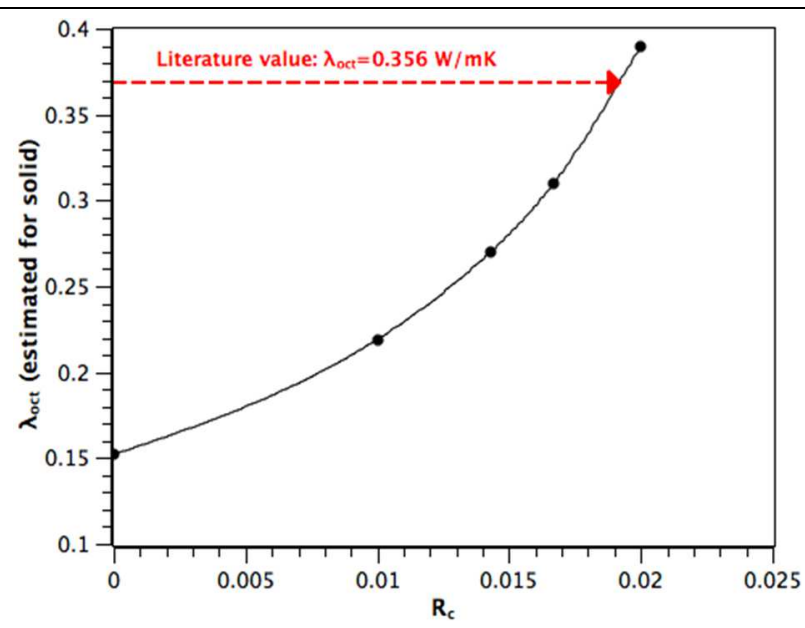

(a)

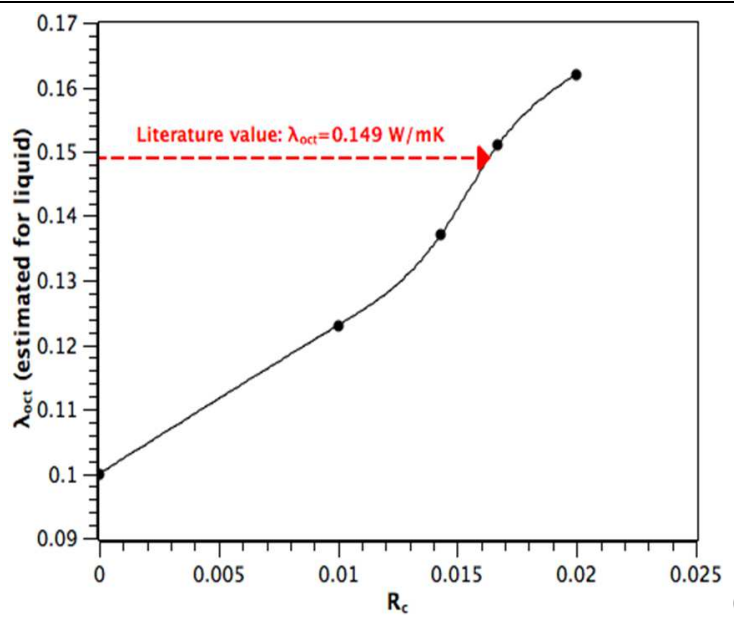

(b)

Figure 5. Estimated thermal conductivity vs. thermal contact resistivity: (a) solid state, (b) liquid state. 


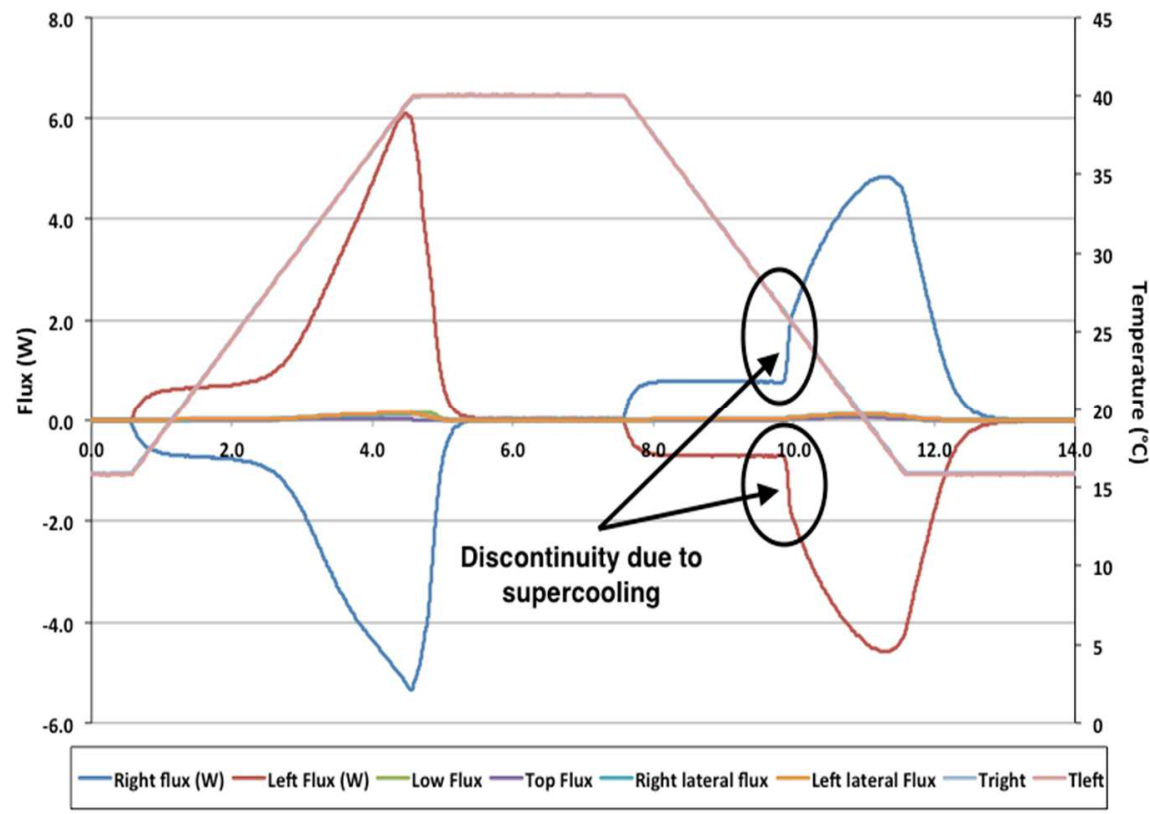

Figure 6. Heat flux curves indicating the presence of supercooling.

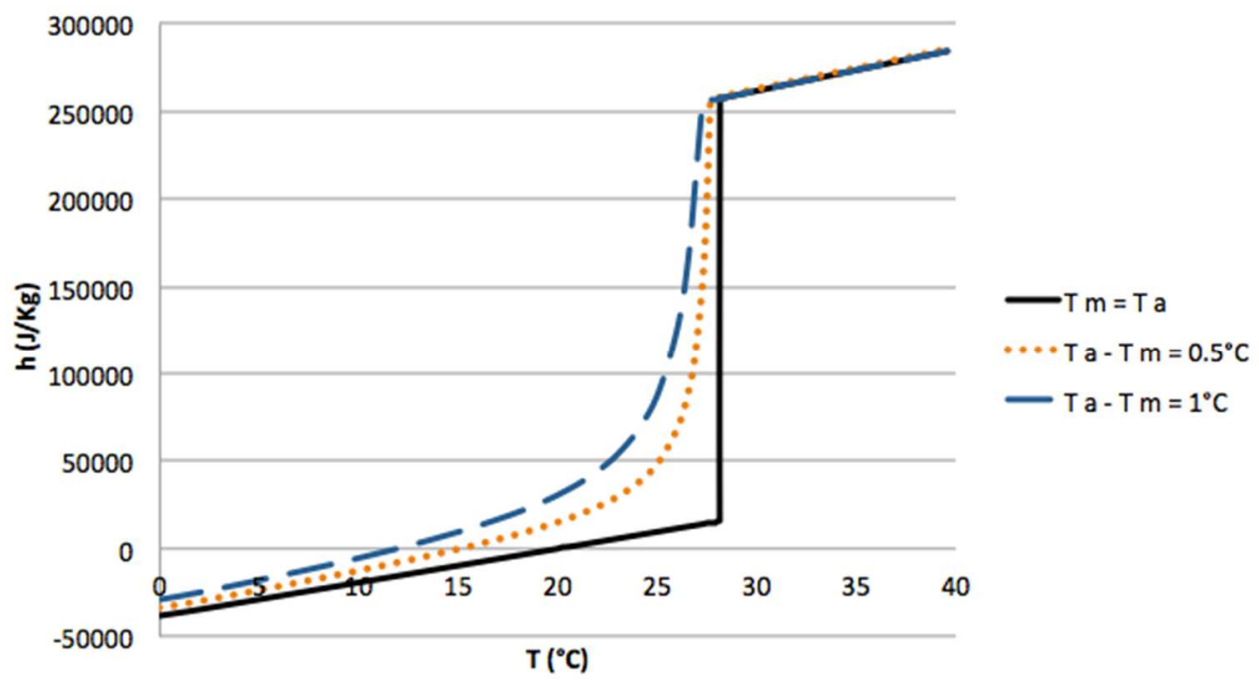

Figure 7. Enthalpy-temperature relationship for different $\left(T_{a}-T_{m}\right)$ values.

773 


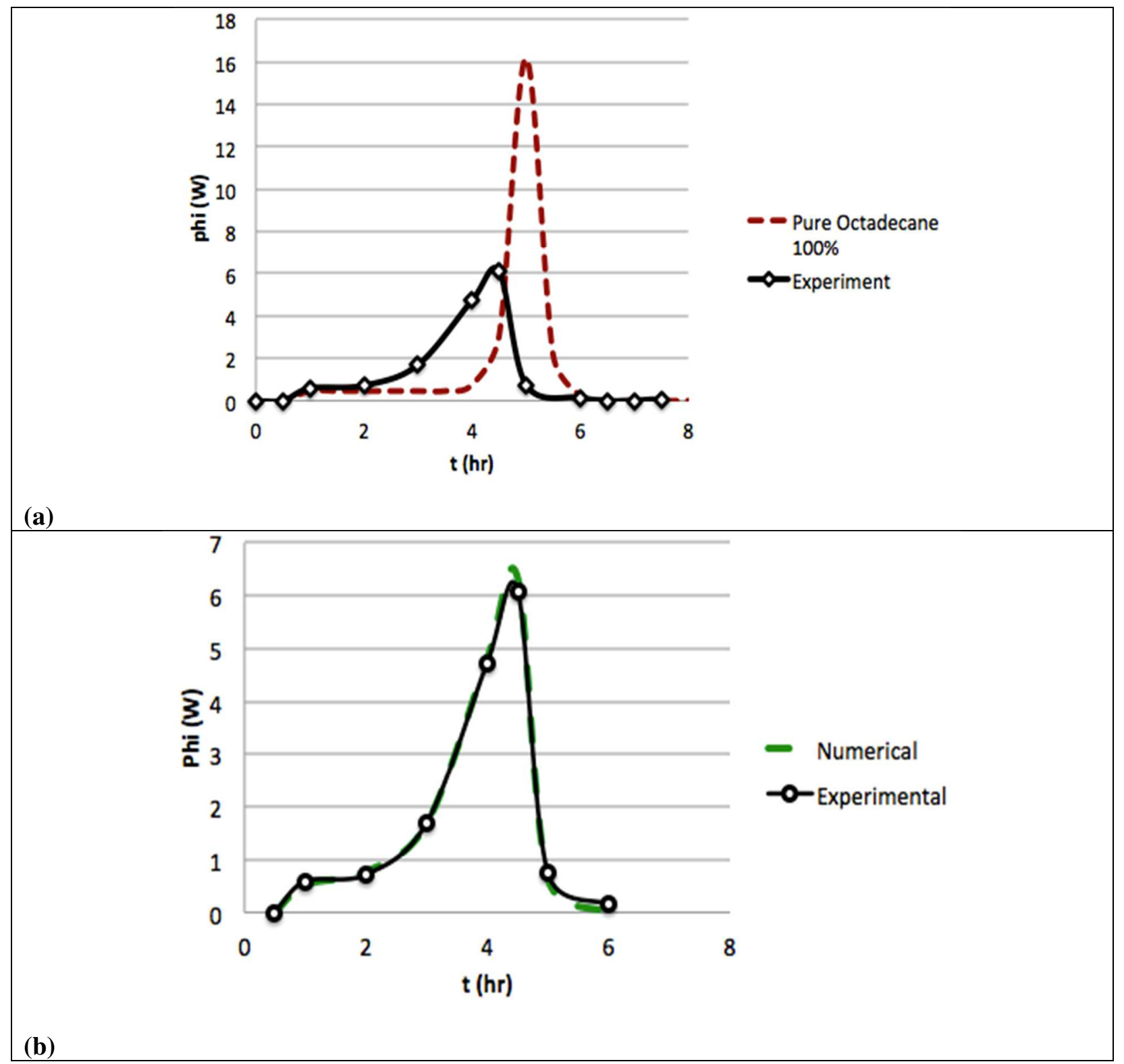

776 Figure 8. Effect of the presence of impurities on the heat flux (a), Numerical and experimental 


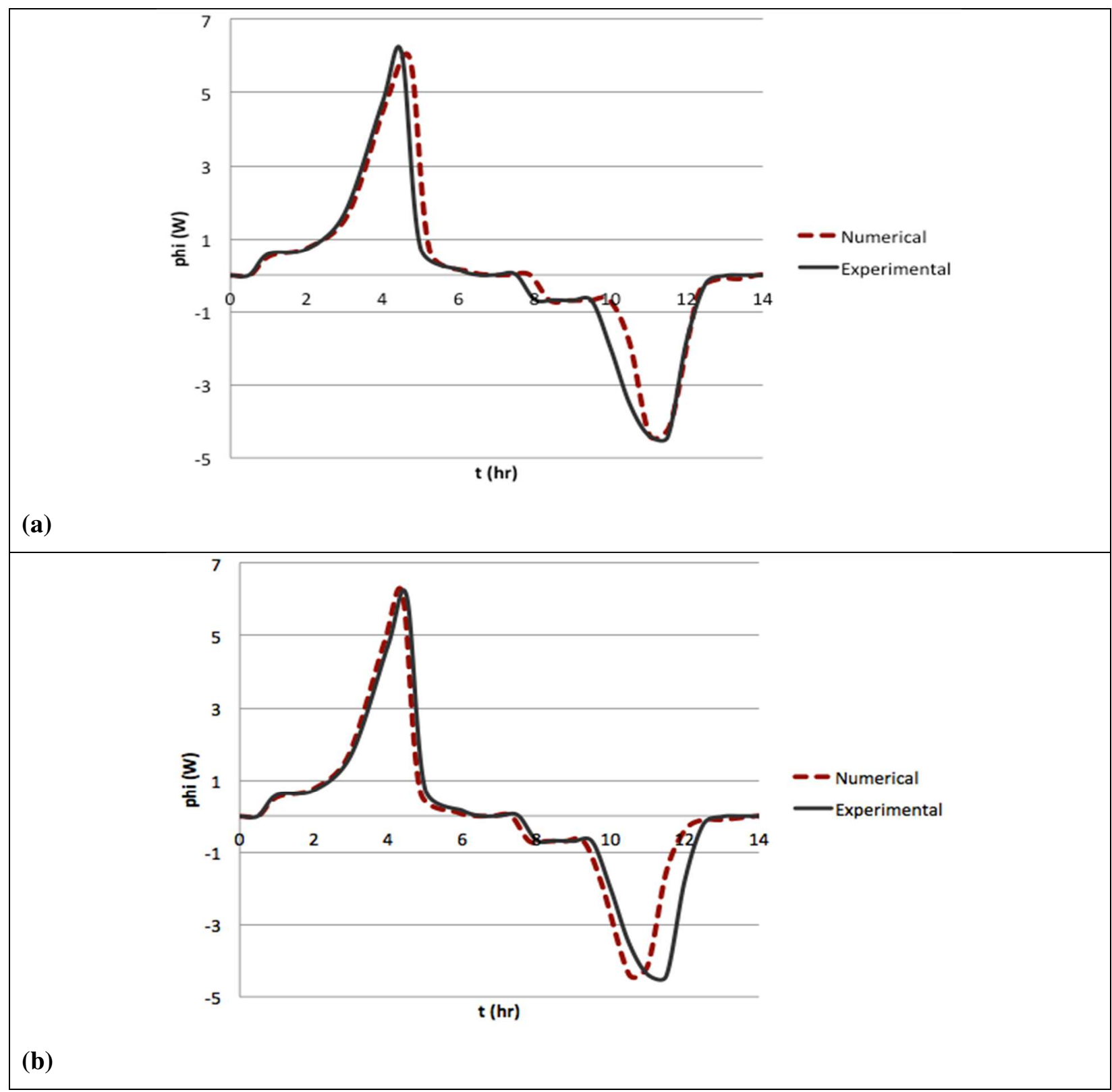

Figure 9. Effect convection on the shape of the heat flux curve: (a) ignoring convection, (b) overestimating convection 


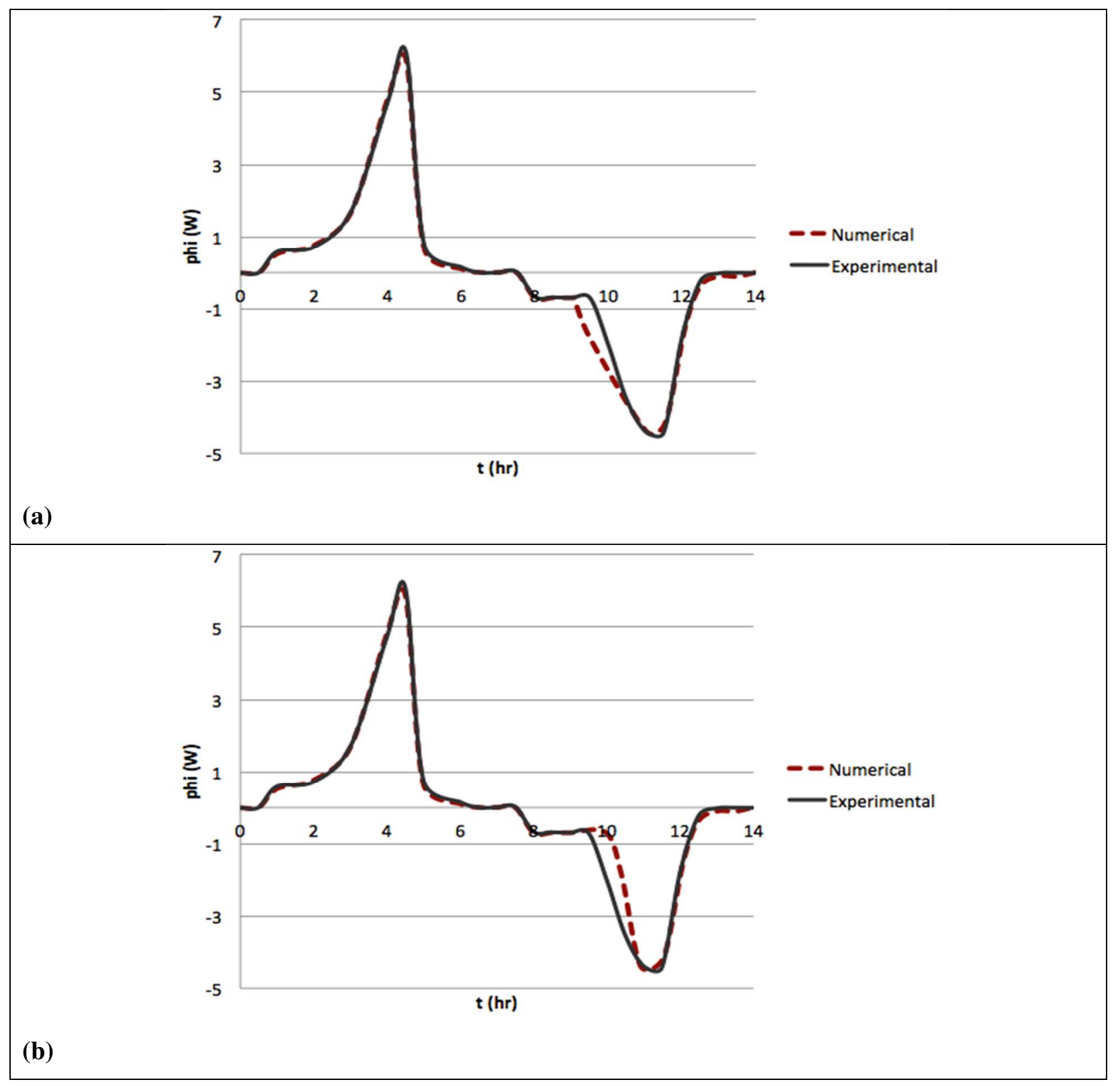

786

Figure 10. Effect supercooling on the shape of the heat flux curve: (a) ignoring supercooling, (b) overestimating supercooling 


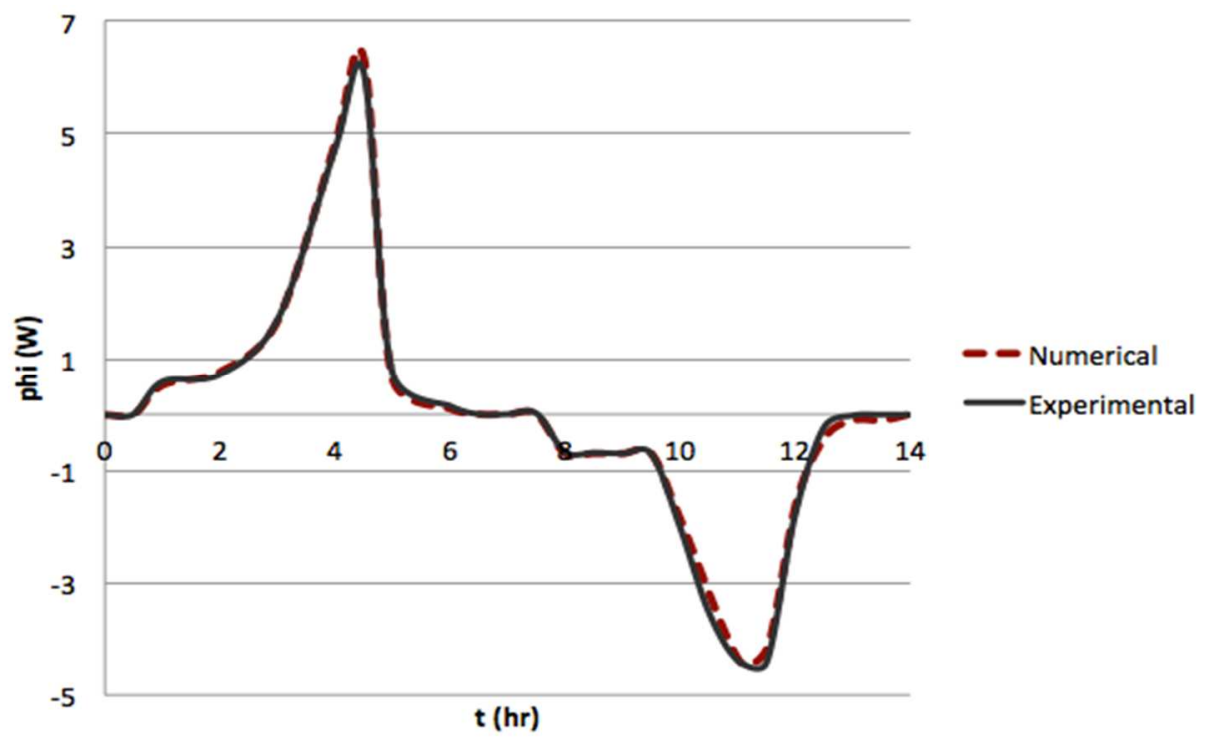

Figure 11. Experimental vs. numerical results when using the enhanced model. 795 